\title{
Are Statistical Reporting Agencies Getting It Right? \\ Data Rationality and Business Cycle Asymmetry*
}

\author{
Norman R. Swanson ${ }^{\dagger}$ \\ Department of Economics \\ Purdue University
}

\author{
Dick van Dijk \\ Econometric Insitute \\ Erasmus University Rotterdam
}

Econometric Institute Report EI 2001-28

September 2001

*This research was initiated while both authors were visiting the Department of Economics, University of California at San Diego. The hospitality and stimulating research environment provided are gratefully acknowledged. We thank Clive W.J. Granger and Allan Timmerman for helpful comments and discussions. The second author acknowledges financial support from the Netherlands Organization for Scientific Research (N.W.O.).

${ }^{\dagger}$ Department of Economics, Krannert School of Management, Purdue University, West Lafayette, IN 47907-1310, USA, email: nswanson@mgmt.purdue.edu

$\ddagger$ Econometric Institute, Erasmus University Rotterdam, P.O. Box 1738, NL-3000 DR Rotterdam, The Netherlands, email: djvandijk@few.eur.nl 


\begin{abstract}
This paper provides new evidence on the rationality of industrial production (IP) and the producer price index (PPI). However, rather than examining preliminary and fully revised data, as is usually the practice, we examine the entire revision history for each data series. Thus, we are able to assess whether earlier releases of data are in any sense "less" rational than later releases, for example, and when early releases of data become rational. Our findings suggest that seasonally unadjusted IP and PPI become rational after approximately 3-4 months, while seasonally adjusted versions of these series remain irrational for at least 12 months after initial release. Additionally, we find that there is a clear increase in the volatility of early data releases during recessions, suggesting that early data are less reliable in tougher economic times. One feature of the approach that we take is that we are able to include revision histories in the information sets used to examine the rationality of a particular release of data. This in turn allows us to assess whether the revision process itself is predictable from its own past, hence possibly leading to rules for the construction of "better" preliminary releases of data. For most of the variables examined, we find evidence of this form of predictability. Another feature of the approach taken in the paper is that we are able to provide evidence suggesting that nonlinearities in economic behavior manifest themselves in the form of nonlinearities in the rationality of early releases of economic data. This is done by separately analyzing expansionary and recessionary economic phases and by allowing for structural breaks. These types of nonlinearities are shown to be prevalent, and in some cases incorrect inferences concerning unbiasedness and efficiency arise when they are not taken account of. For example, seasonally unadjusted IP data become unbiased much more quickly after 1980 than before 1980. Additionally, seasonally adjusted IP data take less time to become efficient during expansions than during recessions.
\end{abstract}

Keywords: efficiency, real-time data set, unbiasedness.

JEL Classification Codes: E100, E300, E420. 


\section{Introduction}

The construction of accurate preliminary announcements of macroeconomic variables remains an area of key importance to researchers and policymakers alike. The reasons for this are many. For example, optimal policy making behavior is dependent on accurate assessments of the state of the economy, which implies that researchers constructing empirical models for use in policymaking are faced with the task of ensuring that the data used correspond as closely as possible to those data policymakers are interested in. The latter issue is sometimes ignored, as it is not always noted that a vector realization of a given macroeconomic variable available at a given point in time is actually comprised of many different "releases" of data (i.e. the most recent observations are preliminary releases, while the most distant observations are "final" releases). The empirical modeler often uses such data when constructing econometric estimators, for example, even if subsequent revisions ensure that the data used ex post by the modeler are not the same as those used ex ante by the policymaker. Note also that the policymaker is interested in the "truth". For example, if the modeler is constructing a model of inflation, the policymaker would like to assume that the modeler is using "true" price data. However, many of the data used by the researcher are early releases, and therefore subject to revision. Thus, both the researcher and the policymaker are interested in ascertaining whether early releases of data, when viewed as predictions of final or "true" data are efficient, or rational, using the terminology of Muth (1961).

The above notions have led to a huge literature on two different fronts. On one front, the rationality of late predictions and early releases of data has been studied extensively, while on the other front, the revision processes of macroeconomic variables have been examined in much detail. A partial list of the many publications in the area include: Morgenstern (1963), Stekler (1967), Howrey (1978), Zarnowitz (1978), Pierce (1981), Boschen and Grossman (1982), Mankiw, Runkle and Shapiro (1984), Mankiw and Shapiro (1986), Mork (1987), Milbourne and Smith (1989), Keane and Runkle (1989, 1990), Diebold and Rudebusch (1991), Neftçi and Theodossiou (1991), Kennedy (1993), Kavajecz and Collins (1995), Mariano and Tanizaki (1995), Rathjens and Robins (1995), Hamilton and Perez-Quiros (1996), Gallo and Marcellino (1999), Faust, Rogers and Wright (2000), Amato and Swanson (2001), Bernanke and Boivin (2001), Croushore and Stark (2001), and the references contained therein. Three features tie these papers together. First, many of them are concerned with either GDP or money data. Exceptions include: Diebold and Rudebusch (1991) and Hamilton and Perez-Quiros (1996), who examine the predictive 
content of the composite leading index in real-time; Keane and Runkle (1990), who evaluate the rationality of price forecasts; and Kennedy (1993), who considers data on the index of industrial production. Second, the focus in these papers is largely on comparing first available or "preliminary" with fully revised or "final" data. One reason for this is that data on the entire revision process for macroeconomic variables has been largely unavailable until recently. From the above list of references, only Amato and Swanson (2001), Bernanke and Boivin (2001), and Croushore and Stark (2001) have considered complete revision histories for the variables that they examine, although there is a burgeoning literature in the area. ${ }^{1}$ Finally, a common theme in these papers is that the rationality (or lack thereof) of predictions of final data has been assumed to be constant with respect to the business cycle and constant over time.

In this paper, we add to the literature on assessing the rationality of preliminary data by examining seasonally adjusted and unadjusted time series for industrial production (IP) and the producer price index for finished goods (PPI). A number of features of our analysis differentiate our work from earlier research. First, we have constructed monthly "real-time" data sets which include the entire revision history of the variables that we examine. This means that for each calendar date, we have a complete historical time series for each variable at our disposal. Each of these time series corresponds to the actual data that were available on the particular calendar date in question. Thus, we can inspect the entire revision process in detail, rather than just looking at the properties of first versus final releases of data, for example. One reason why this is important is that we are now able to assess whether earlier releases are in any sense "less rational" than later releases. Put another way, we can measure how long it takes before the observed data become rational. In addition, we can include revision histories in the information sets used to examine the rationality of a particular release of data. This allows us to assess whether the remaining revision is predictable from its own past, suggesting in turn whether revision histories can be used to construct "better" preliminary releases of data. Second, we recognize that business cycle asymmetry is a stylized characteristic of economic activity, and argue that there is no reason to preclude the possibility that nonlinearities in economic behavior manifest themselves in the form of nonlinearities in the rationality of early

\footnotetext{
${ }^{1}$ The Croushore and Stark (2001) data are all quarterly, have been compiled by Dean Croushore of the Federal Reserve Bank of Philadelphia, and are available at http://www.phil.frb.org/econ/forecast/reaindex.html. The data sets that we have constructed are all monthly.
} 
releases of economic data. ${ }^{2}$ A number of papers recognize that nonlinearities may be present in the rationality of preliminary GDP data, including Brodsky and Newbold (1994) and Rathjens and Robins (1995), although they do not examine the entire revision process, and do not explicitly consider any particular type of nonlinearity. We, on the other hand, directly test whether nonlinearities are present in the revision process based on separate analysis of expansionary and recessionary economic episodes. The distinction between expansionary and recessionary episodes is useful because it allows us to determine the extent to which preliminary announcements are useful in different phases of the business cycle. For example, we shall see that early releases of data may be rational during expansions while they are irrational during recessions. Third, there is a growing body of evidence showing that the statistical (business cycle) properties of US macroeconomic variables, output and inflation in particular, have changed during the post World War II period, see Watson (1994), Stock and Watson (1996), McConnell and Perez-Quiros (2000), Blanchard and Simon (2001), Kahn, McConnell and Perez-Quiros (2001), Chauvet and Potter (2001), and Sensier and van Dijk (2001) among others. The explanations for these changes range from technological change, such as improvements in inventory management and information technology, to improved monetary policy. In this paper we investigate whether the revision processes of industrial production and inflation have also been subject to structural breaks, and we argue that changes in the rationality of early data releases that arise over time may be caused by improvements in the data collection and processing techniques used by the statistical agencies. When we find structural breaks and/or business cycle asymmetry, we re-estimate all of the regression models that are used to test for rationality, taking the relevant nonlinearities into account.

Our findings suggest that seasonally and unadjusted IP releases remain biased for approximately 3 months, and remain inefficient for 3-4 months, while unadjusted PPI releases are biased for approximately 4 months and inefficient for 4-5 months. Thereafter, though, subsequent releases have no useful information in them. Seasonally adjusted IP and PPI data, on the other hand, remain both biased and inefficient for at least 12 months. This suggests, for example, that investors on Wall Street should not react to preliminary unadjusted industrial production releases after 4 months, as all later releases contain little or no useful information. Additionally, these findings provide a rule of thumb for agents and/or policy makers who are

\footnotetext{
${ }^{2}$ See e.g. Diebold and Rudebusch (1996), Ramsey and Rothman (1996) and Granger (2001) for discussions of business cycle asymmetry.
} 
interested in knowing when preliminary IP and PPI data releases become rational.

One feature of all of our irrationality findings is that for most variables, the past of the revision process appears useful for predicting fully revised data, ex ante. This suggests that rules might be constructed for the improvement of early data releases, although it should be stressed that the explanatory power of the efficiency regressions is quite small in general, and that further evidence in this area is needed before firm conclusions can be drawn (see e.g. Faust, Rogers, and Wright (2000) for further discussion).

We find evidence of both structural breaks and business cycle nonlinearity in the revision process, and find that failure to account for these features of the data in some cases leads to incorrect conclusions concerning unbiasedness and efficiency. Furthermore, efficiency and unbiasedness findings frequently depend on the stage of the business cycle, and have changed over time. For example, seasonally adjusted IP releases become efficient more quickly during expansions than during recessions. Additionally, unbiasedness is achieved more slowly for IP data pertaining to calendar dates prior to 1980 than after 1980. However, no clear pattern emerges for seasonally adjusted data, which may be a result of the application of nonlinear seasonal adjustment filters (see e.g. Ghysels, Granger and Siklos (1996) for further discussion of the seasonal adjustment filters currently used by statistical reporting agencies).

Another feature of the revision process worth noting here is that volatility of early data revisions increases during recessions, suggesting that early releases are less reliable in tougher economic times. This feature is particularly prevalent for industrial production data, although it clearly characterizes price data as well. For example, the differential between volatilities in first reported IP data is $25 \%$ for NSA data and a startling 150\% for SA data, during expansionary and recessionary phases, with recessionary phases exhibiting the higher volatility. ${ }^{3}$ There are many possible explanations of this phenomenon. For example, firms facing hard times are less apt to report accurate measures of their performance, for fear of causing strong selling pressures on their stocks. For this reason, firms may be more likely to try to withhold bad information as long as possible, in hopes that the economy will have rebounded by the time they report, hence leading to less dramatic stock price reductions. Additionally, statistical reporting agencies may have more difficulty obtaining timely and/or accurate production data from firms facing more volatile recessionary pressures than when the economy is expanding. The preceding notions are supported by the fact that industrial production releases are by and large more

\footnotetext{
${ }^{3}$ See the second last two columns in the lower panels of Tables 1 and 2.
} 
biased and less efficient during recessions than during expansions, for example.

By examining the entire revision process of output and prices, we believe that we contribute not only to the discussion of the rationality of early releases of economic data, but also to the methodology of examining this and related issues. One dimension of our contribution is that we uncover and quantify the differences in the rationality of first and subsequent releases of economic data. A second feature is that we account for business cycle asymmetry and structural breaks when carrying out tests of rationality. The rest of the paper is organized as followed. Section 2 contains a summary of the methodology used in the paper, as well as a brief discussion of previous research. In Section 3, we introduce our real-time data sets and describe the main features of the revision processes, while Section 4 contains our empirical findings from the rationality tests. Conclusions are gathered in Section 5.

\section{Methodology}

\section{$2.1 \quad$ Tests of Rationality}

In the sequel, the following notation is used. Let ${ }_{t+k} X_{t}$ denote the value of the (annualized) monthly growth rate of a variable of interest which pertains to calendar date $t$ as it is available at time $t+k$. In this setup, if we assume a one month reporting lag, then first release or "preliminary" data are denoted by ${ }_{t+1} X_{t}$. In addition, we denote fully revised or "final" data, which is obtained as $k \rightarrow \infty$, by ${ }_{f} X_{t}$. Our notation is necessary because we are interested in examining the entire revision process, not just preliminary and final releases, as is commonly done in the studies cited in the introduction.

Research in the area of testing for the rationality of preliminary announcements is based almost exclusively on regression models of two types linking the first and final releases of data, put forward by Mankiw, Runkle and Shapiro (1984). Using the notation introduced above, and assuming that the value of $X$ measured at time $t$ by the reporting agency is the value of $X$ reported at time $t$, the first type of regression model examined by Mankiw et al. (1984) can be written as:

$$
{ }_{t+1} X_{t}=\alpha+\beta_{f} X_{t}+\varepsilon_{t+1}
$$

where $\varepsilon_{t+1}$ is an error term that is assumed to be uncorrelated with ${ }_{f} X_{t}$. This model is used to test the errors-in-variables hypothesis discussed in Mankiw et al. (1984). In particular, the null hypothesis is that the preliminary announcement ${ }_{t+1} X_{t}$ is equal to the final observation ${ }_{f} X_{t}$ plus measurement error (i.e. $\alpha=0$ and $\beta=1$ ). 
As discussed in Mankiw et al. (1984), failure to reject this hypothesis is equivalent to a finding that the preliminary data are unconditionally unbiased predictions of the final data. However, the predictions may be conditionally biased. Based on an examination of preliminary and final money stock data, Mankiw et al. (1984) fail to reject the null hypothesis of unconditional unbiasedness.

In order to lend further support to their finding in favor of an errors-in-variables model of preliminary money data, Mankiw et al. (1984) also run regressions of the following form:

$$
{ }_{f} X_{t}=\alpha+\beta_{t+1} X_{t}+W_{t+1}^{\prime} \gamma+\varepsilon_{t+1},
$$

where $W_{t+1}$ is an $m \times 1$ vector of variables representing the conditioning information set available at time period $t+1$ and $\varepsilon_{t+1}$ is an error term assumed to be uncorrelated with ${ }_{t+1} X_{t}$ and $W_{t+1}$. The null hypothesis of interest in this model is that $\alpha=0$, $\beta=1$, and $\gamma=0$. This hypothesis is based on the notion of testing for rationality of ${ }_{t+1} X_{t}$ for ${ }_{f} X_{t}$ by finding out whether the conditioning information in $W_{t+1}$, available in real-time to the data issuing agency, could have been used to construct better conditional predictions of final data. Notice that this hypothesis, if rejected, is consistent with the errors-in-variables hypothesis and the notion that the predictions may be conditionally biased even when they are unconditionally unbiased. Mankiw et al. (1984) find evidence in favor of rejection of the null that $\alpha=0, \beta=1$, and $\gamma=$ 0 . Thus, their ultimate conclusion is that preliminary money stock announcements are not rational, and are an example of the classical errors-in-variables problem.

In the literature subsequent to Mankiw et al. (1984), attention has focused primarily on forming regression models of the second type above (see e.g. Campbell and Ghysels (1995), Kavajecz and Collins (1995), and the references contained therein). Contributions to this literature include the finding by Kavajecz and Collins (1995) that seasonally unadjusted money announcements are rational while adjusted ones are not. In addition, a vast number of papers which focus on GDP have been published, including most of those listed in the introduction. The evidence here is mixed. For example, Mankiw and Shapiro (1986) find little evidence against the null hypothesis of rationality, while Mork (1987) and Rathjens and Robins (1995) find evidence of irrationality, particularly in the form of prediction bias (i.e. $\alpha \neq 0$ in (2)). The only paper which uses industrial production to measure output is Kennedy (1993), who finds substantial evidence of irrationality. Finally, Keane and Runkle (1990) look at the efficiency of price forecasts using survey forecasts rather than preliminary (or real-time) data when testing rationality. In their paper, they use the novel approach of constructing panels of real-time survey predictions. This allows 
them to avoid aggregation bias, for example, and is one of the reasons why they find evidence supporting rationality, although previous studies focusing on price forecasts had found evidence to the contrary. Croushore and Stark (2001) are the only ones who explicitly examine many different releases of data, although they focus on correlations across data releases and consider only quarterly consumption data.

One reason why so much attention has been placed on the second type of regression model is that, using Muth's (1961) notion of rational expectations, the preliminary release ${ }_{t+1} X_{t}$ is a rational forecast of the final data ${ }_{f} X_{t}$ if and only if

$$
{ }_{t+1} X_{t}=\mathrm{E}\left[{ }_{f} X_{t} \mid \Omega_{t+1}\right]
$$

where $\Omega_{t+1}$ the information set available at time $t+1$. Following Keane and Runkle (1990), the test of rationality of ${ }_{t+1} X_{t}$ in the context of the model (2) can be broken down into two sub-hypotheses, namely (i) unbiasedness and (ii) efficiency. The hypothesis of unbiasedness can be tested by imposing the restriction that $\gamma=0$ and testing $\alpha=0, \beta=1$, while efficiency requires that $\alpha=0, \beta=1$, and $\gamma=0$. For further details on the relationship between errors-in-variables hypotheses and rationality hypotheses, the reader is referred to Faust, Rogers, and Wright (2000), where the errors-in-variables model is associated with the notion of "noise" and the rational forecast model is associated with "news". In the sequel, we shall focus our attention exclusively on the notion of rationality and the associated unbiasedness and efficiency hypotheses outlined above.

One feature of our approach that differentiates it from that of previous authors is that we have the entire revision history for each variable. Thus, for example, we are able to examine the rationality of any release of data. This capability is useful because early releases of data may be inefficient while later releases are efficient, and it is useful for agents and/or policy-makers to know exactly when early data releases become rational, particularly if they are interested in equating early data releases with efficient predictions of final data (see below for further discussion). In addition, we are able to assess whether the data revision process itself is predictable. These sorts of questions, as well as those addressed by earlier researchers in the area, can be answered by generalizing (2) in the following fashion:

$$
{ }_{f} X_{t}-{ }_{t+k} X_{t}=\alpha+\beta_{t+k} X_{t}+W_{t+k}^{\prime} \gamma+\varepsilon_{t+k},
$$

where $k=1,2, \ldots$ defines the release of data (that is, for $k=1$ we are looking at preliminary data, for $k=2$ the data being examined has been revised once, etc.).

Note that in (4) we may examine the rationality of different releases of data by considering different values of $k$. In particular, this regression model allows 
us to assess whether later releases of data are more or less rational than earlier releases. This may enable us to distinguish between "temporary inefficiency" and "permanent inefficiency". On the one hand, inefficiency may arise simply because preliminary data releases are constructed using incomplete information sets. For example, if releases are based on reported firm production levels, say, and some firms are "late" in reporting, then predictions of missing production levels may be used when constructing preliminary data releases, and these predictions may be inefficient. Over time, however, as the missing production data become available, newer releases may be expected to be "more" efficient. In this scenario, it follows that after some reasonable amount of time, all subsequent data releases are efficient. We call this situation "temporary inefficiency". As mentioned above, knowledge of the point in time after which releases of data are efficient has implications for policymakers, for example. On the other hand, inefficiency may also arise because of systematic factors. For example, data releases based only on survey information can never be completely accurate. This opens up the possibility for inefficiencies to be carried far into the future. We refer to this type of situation as "permanent inefficiency".

Notice that in (4), the null hypotheses of interest are now that $\alpha=\beta=0$, given that $\gamma=0$ (unbiasedness) and $\alpha=\beta=\gamma=0$ (efficiency). Finally, for $k>1$, notice that we may define $W_{t+k}$ to include certain characteristics of the revision history, such as the revision between the first and $k^{\text {th }}$ release ${ }_{t+k} X_{t}-{ }_{t+1} X_{t}$. Thus, we are able to examine whether inefficiency arises via information available in the revision history for a given release of data as well as through other sources.

A further generalization of (4) is given by the model

$$
{ }_{t+l} X_{t}-{ }_{t+k} X_{t}=\alpha+\beta_{t+k} X_{t}+W_{t+k}^{\prime} \gamma+\varepsilon_{t+k}
$$

where $k<l$, which considers the revision between the $k^{\text {th }}$ and $l^{\text {th }}$ release of data. The model given in (5) is not examined in this paper. However, it is worth noting that by fitting models of the form given by (5), we may examine the rationality of a particular release of data relative to later releases of data. In the sequel, however, we focus on (4).

\subsection{Rationality and the Business Cycle}

The conceptualization and characterization of business cycles has been the subject of innumerable studies since the seminal work of Burns and Mitchell (1946). A very small selection of papers in this area include Shapiro and Watson (1988), Ramey 
(1991), King and Watson (1996), Stock and Watson (1999) and the references contained therein. In this section, we stress that our real-time data sets are useful for examining a number of features of macroeconomic data for which little is known, including asymmetry in data release rationality and in the length of time needed before data releases become efficient.

There are several types of nonlinearity that may affect inference based on fitting regression models of the form given by (4). For example, data release efficiency may be dependent on the stage of the business cycle. This may arise if government reporting agencies are conservative during expansionary periods (e.g. they tend to under-report economic growth estimates so as not to "over-heat" expectations and hence growth), and are liberal during contractionary periods (e.g. they may tend to overestimate economic growth estimates so as not to exacerbate already worsening economic expectations), thereby leading to self-fulfilling cycles of economic decline (see e.g. Chauvet and Guo (2001), among others). This would lead to differing levels of efficiency for different observations in the same release of data, depending on whether they pertain to calendar months during expansionary or contractionary periods. Another reason why the speed with which data releases become efficient may depend on the business cycle is that firms may be more timely and/or accurate during "good" times. In troubled times, firms may be more apt to under-report losses, or may simply take longer to file results (see above for further discussion).

Our approach to the issue of business cycle asymmetry effects on rationality is to test for asymmetric unbiasedness and efficiency by fitting models of the form:

$$
\begin{aligned}
{ }_{f} X_{t}-{ }_{t+k} X_{t}=\left(\alpha_{1}+\beta_{1+k} X_{t}+\right. & \left.W_{t+k}^{\prime} \gamma_{1}\right) \mathrm{I}\left[s_{t}=0\right] \\
& +\left(\alpha_{2}+\beta_{2 t+k} X_{t}+W_{t+k}^{\prime} \gamma_{2}\right) \mathrm{I}\left[s_{t}=1\right]+\varepsilon_{t+k},
\end{aligned}
$$

where $s_{t}=0(1)$ if calendar month $t$ is part of an expansion (recession), which is defined using the NBER-dated business cycle peaks and troughs, and where I[.] is an indicator variable, taking the value 1 if its argument is true and 0 otherwise. Tests for this type of nonlinearity are all based on checking the equality of coefficients in the above regression model. For example, consider the case where we are only interested in testing unbiasedness in expansions and recessions, so that $\gamma_{1}=\gamma_{2}=0$ is assumed to hold. Upon rejecting the hypothesis of linear unbiasedness $\alpha=\beta=0$ in (4) (with $\gamma=0$ imposed), we may test for asymmetry in the (un)biasedness properties by testing the null hypothesis $\alpha_{1}=\alpha_{2}$ and $\beta_{1}=\beta_{2}$ in (6). In cases where we find such asymmetry, we re-run all of our rationality tests by splitting the data into recessionary and expansionary phases. This allows us to ascertain whether 
absence of rationality in the entire sample is due primarily to a lack thereof during recessionary periods, for example.

Related sorts of asymmetries may also show up in exploratory data analysis of the revision process itself. For example, it may turn out that the mean revision of a series is of opposite sign or different in magnitude during expansionary periods than during recessionary periods. A finding of this type would further support the hypothesis of business cycle asymmetry in the rationality of data releases, and might also suggest whether preliminary data are more or less accurate during expansions, for example. If the government knows that preliminary releases available during recessions are not only inefficient, but also biased downwards, for example, they can adjust policy rules to account for this fact. To the best of our knowledge, no research in this area has yet been reported.

Another type of nonlinearity that may affect our findings is the presence of structural breaks in the data generating processes of the variables themselves. To explore this possibility, we also check for structural breaks in the unbiasedness and efficiency test regressions based on (4). ${ }^{4}$ Given appropriate estimates of possible break dates, we also construct unbiasedness and efficiency tests on pre- and postbreak samples, in order to assess whether our findings are driven by non-robustness of standard efficiency tests to structural change, for example, and in order to ascertain whether there have been improvements in data collection and processing methods used by statistical reporting agencies during our sample period (see e.g. Rathjens and Robins (1993) for further discussion).

Estimation of all models in the sequel is carried out by least squares, with reported test statistics all based on heteroskedasticity and autocorrelation consistent

${ }^{4}$ In particular, we use the sup-Wald test as developed by Andrews (1993):

$$
\operatorname{SupW}=\sup _{\tau_{1} \leq \tau \leq \tau_{2}} W_{T}(\tau)
$$

where $W_{T}(\tau)$ denotes a Wald statistic of the hypothesis of constancy of the parameters $\alpha, \beta$ and $\gamma$ in (4) against the alternative of a one-time change for fixed break data $\tau$, given by

$$
\begin{aligned}
{ }_{f} X_{t}-{ }_{t+k} X_{t}=\left(\alpha_{1}+\beta_{1+k} X_{t}+W_{t+k}^{\prime} \gamma_{1}\right) \mathrm{I}[t & <\tau] \\
& +\left(\alpha_{2}+\beta_{2 t+k} X_{t}+W_{t+k}^{\prime} \gamma_{2}\right) \mathrm{I}[t \geq \tau]+\varepsilon_{t+k}
\end{aligned}
$$

All tests are computed by imposing $15 \%$ symmetric trimming (i.e. we set $\tau_{1}=[\pi T]$ and $\tau_{2}=$ $[(1-\pi) T]+1$ with $\pi=0.15$, where [.] denotes integer part and $T$ is the sample size). The value $\tau_{B}$ that minimizes the sum of squared residuals corresponding to (8) is taken to be the estimate of the break date. Note also that as we have structural change in the revision process, we should in principle construct p-values for our unbiasedness and efficiency regressions using the methodology of Hansen (2000). However, in our case the distortions to relevant p-values are small, and so we report only the standard p-values. 
standard error estimators.

\section{Real-Time Data}

We have collected seasonally adjusted (SA) and unadjusted (NSA) real-time monthly data for U.S. industrial production (IP) and the producer price index for finished goods (PPI). Although all data are available in levels, we examine only (annualized) monthly growth rates in this paper. This allows us to ignore issues relating to unit roots and cointegration (see e.g. Engle and Granger (1987)), and to avoid the problem of accounting for pure base year changes ${ }^{5}$ when comparing multiple revisions of data for a particular calendar date. In addition, the use of growth rates allows for comparison of our findings with those of Mankiw, Runkle and Shapiro (1984) and Kavajecz and Collins (1995), for example.

For all variables, a first estimate (i.e. the preliminary data release) for a given month is released about 15 days after the end of the month. Hence, ${ }_{t+k} X_{t}$ is usually available for $k=1,2, \ldots$. Following Diebold and Rudebusch (1991), it is convenient to think of a real-time data set as being organized in a matrix, with rows corresponding to calendar dates $t=1, \ldots, T$ and columns corresponding to release dates $k_{0}, \ldots, T+k_{1}$, for $k_{0}>1, k_{1}>1$, and where $T$ is the sample size used in the empirical analysis. Thus, each column of a real-time data set corresponds to the actual data that a forecaster or decision maker would have had available at a certain point in time. In the discussion below, we refer to the release date as the "vintage" of the data. Note that by fixing $k_{1}>1$, we guarantee that all of the calendar observations in our data set have been revised at least $k_{1}-1$ times. This in turn allows us to compare preliminary predictions with final releases, for example.

The number of vintages for which we have historical real-time data varies by series. In particular, for NSA IP, SA IP, and NSA PPI, the first vintage is 1963:1, and the last vintage is 2001:1, with historical data for each vintage going back to 1962:12. For SA PPI, the analogous dates are 1978:2-2001:1 and 1978:1. To facilitate comparison of the results of NSA and SA PPI, we use the NSA data from 1978:1 onwards only. In the sequel we examine data for calendar periods up until 1998:12. We use the time series (or vintage) available in 2001:1 for the calendar period up until 1998:12 as our "final" data, i.e. $k_{1}=37$ in the notation discussed above. This being said, it should be noted that we can never claim to have a final record of

\footnotetext{
${ }^{5}$ By a "pure base year change" we mean that data is revised only because of a base year change, without regular or definitional revisions occurring at the same time.
} 
historical data which is immune from potential future revision. In addition, it is worth noting that we could also have assumed, for example, that all data are "final" after 24 releases, say. In our context, though, this makes little difference, as we remove the effect of all benchmark revisions from our data prior to carrying out unbiasedness and efficiency tests; and in our data sets, little revision other than the benchmark variety occurs after 24 months. ${ }^{6}$

The real-time industrial production data sets have been compiled from historical issues of the Federal Reserve Bulletin and the Survey of Current Business. Recent releases of IP data are available on the Federal Reserve Board's website at http://www.federalreserve.gov/releases/G17/. In addition, a file containing the first five releases of seasonally adjusted IP from 1972:1 onwards has been made available electronically. All of the data for PPI have been gathered from issues of the Survey of Current Business, National Economic Trends, and Business Statistics. Recent data are available on the web-site of the Bureau of Labor Statistics at http://stats.bls.gov/ppihome.html.

A typical release of industrial production (IP) data consists of a first release for the previous month and revisions for the preceding one to five months (due to the availability of new source data and the revision of source data). In addition, more comprehensive re-benchmarking revisions and base-year changes occur from time to time, which affect the entire (or at least a large part of the) historical time series. During our sample period, base-year changes occurred in September 1971, July 1985, April 1990 and February 1997. In addition, major revisions due to rebenchmarking occurred in July 1976, May 1993, December 1994, February 1997 (only for the seasonally adjusted series), and annually as of December 1997. See Kennedy (1993), Robertson and Tallman (1998) and Swanson, Ghysels and Callan (1999) for additional discussion of the revision process of industrial production.

The real-time data sets for the producer price index (PPI) involve more infrequent revision. In fact, most observations on seasonally adjusted PPI are revised only once, four months after their original release dates. The same applies to the seasonally adjusted PPI, although for these data additional "periodic" revisions occur at approximately 12 month intervals (usually February of each year). These periodic revisions involve incorporating "more comprehensive information" and usually affect data for the preceding 12-15 months. Non-benchmark revisions do not occur

\footnotetext{
${ }^{6}$ In fact, for the NSA and SA PPI data, non-benchmark revisions occur only during the first 7 and 19 releases, respectively. For NSA and SA IP, 8.1\% and $14.6 \%$ of the observations is still subject to non-benchmark revisions after 24 months, but the absolute magnitude of these revisions is very small.
} 
anymore after the first 6 and 18 releases for the NSA and SA PPI data, respectively. Finally, there has been no benchmark revision for seasonally unadjusted PPI since 1988, and the base-year was changed only in February 1971 (from 1957-9 to 1967) and February 1988 (to 1982).

Many features of the data can be seen from the plots given in Figures 1-4. In each figure, the first plot is of first available and final release data; the second plot shows the complete revision from preliminary to final release; the third plot is of benchmark revision; and the last plot is of non-benchmark revision. While benchmark revisions often dominate non-benchmark revisions, both types of revision are rather large relative to the actual values of the series shown in the first plot. Thus, there is a possibility that there is useful information in the revision process. This suggests that the approach which we later adopt of including ${ }_{t+k} X_{t}-{ }_{t+1} X_{t}$ in our efficiency and unbiasedness regressions may be important.

In addition to the above real-time data, we have collected data on the 3-month Treasury bill, the spread between yields on 3-month T-bills and 10 year Treasury bonds, the spread between Baa and Aaa rated corporate bonds, the first difference of the log of crude oil prices (West Texas Intermediate Crude), and the dividend re-invested return on the S\&P500. These variables are included in the vector of conditioning variables $W_{t}$ in tests of efficiency, and are similar to those used by previous authors (see Section 1), where more detailed descriptions and motivation for using them can be found.

\section{Empirical Findings}

In this section we begin by discussing the results of a basic statistical analysis of the real-time IP and PPI data. Thereafter, we examine preliminary and later releases of data for unbiasedness and efficiency using the regression framework outlined in Section 2. Because we examine 4 different variables using both linear and nonlinear

models, there are numerous tables of results. For reference, the following chart of tables is thus provided. 
Empirical Results: Organization of Tabular Output

\begin{tabular}{lccccccccc}
\hline \hline & Basic & \multicolumn{2}{c}{ Linear Models } & & \multicolumn{2}{c}{ SC Models } & & \multicolumn{2}{c}{ NL Models } \\
Variable & Statistics & Unb & Eff & & Unb & Eff & & Unb & Eff \\
\hline IP (NSA) & 1 & 6 & 8 & & 12 & 14 & & 16 & 18 \\
IP (SA) & 2 & 6 & 9 & & 12 & 14 & & 16 & 18 \\
PPI (NSA) & 3 & 7 & 10 & & 13 & 15 & & 17 & 19 \\
PPI (SA) & 4 & 7 & 11 & & 13 & 15 & & 17 & 19 \\
\hline \hline
\end{tabular}

Notes: The following acronyms are used: $\mathrm{SC}=$ structural change model, $\mathrm{NL}=$ nonlinear (or asymmetric) business cycle model, $\mathrm{Unb}=$ unbiasedness test regression results, $\mathrm{Eff}=$ efficiency test regression results.

\subsection{Basic Statistical Analysis}

Tables 1-4 report a variety of summary statistics for each variable. These summary statistics include means of the fully revised and first available time series, means of the revisions to the different time series (see columns with the header " $\mu$ "), and means of time series sub-samples determined by: (i) application of the structural change tests discussed above (see columns with the header " $\mu_{1}$ and $\mu_{2}$ " under "Structural Change" - called SC in the above chart and elsewhere ); and (ii) partitioning the data into those available in "expansionary" phases and those available in "recessionary" phases of the business cycle as defined by NBER turning points (see the columns under the heading "Nonlinearity" - called NL in the above chart and elsewhere). Similar results are reported in the lower panel of each table for volatilities (denoted $\sigma, \sigma_{1}$, and $\left.\sigma_{2}\right)$. Statistics are reported for fully revised data $\left({ }_{f} X_{t}\right)$, first available data $\left({ }_{t+1} X_{t}\right)$, the complete revision $\left({ }_{f} X_{t}-{ }_{t+1} X_{t}\right)$, and the components of the complete revision due to "benchmark revisions" (base-year changes and other major revisions) and non-benchmark or regular revisions. In addition, statistics are reported for: (i) "fixed-width revisions" (i.e. ${ }_{t+k+1} X_{t}-{ }_{t+k} X_{t}$ ); (ii) "increasing-width revisions" (i.e. ${ }_{t+k+1} X_{t}-{ }_{t+1} X_{t}$ ); and (iii) "remaining revisions" (i.e. ${ }_{f} X_{t}-{ }_{t+k} X_{t}$ ). These last three types of statistics are computed for "regular revisions", which are defined to be the remaining revisions after removing benchmark revisions from the data. Note that "regular revisions" are of particular interest as these are the only types of revisions used in our unbiasedness and efficiency regression models.

A number of observations can be made based on these tables. First, the fully revised (NSA and SA) IP growth rate is considerably higher than the preliminary announcement growth rate, on average, while for PPI they are very close. Hence, reporting agencies appear to be conservative when reporting the first release of IP. Note that for IP, both benchmark and non-benchmark revisions contribute significantly 
to the complete revision, although the mean non-benchmark revision is about 3.5 times as large as the mean benchmark revision. Additionally, for calendar months in expansionary periods, non-benchmark revisions are about 6 times larger than benchmark revisions, whereas for calendar months in recessionary periods, non-benchmark revisions are about 8 (4) times smaller than benchmark revisions for NSA (SA) data. This feature of the IP revision process suggests that there is business cycle asymmetry associated with the revision process (see below for further discussion).

Second, both first available and fully revised PPI data are characterized by a structural break in mean, which is dated in 1981 (see the first two rows of the Tables 3 and 4). For both NSA and SA data, the post-break mean inflation rate is substantially lower than that for the pre-break period. For IP, evidence in favor of structural breaks is much weaker, with only seasonally adjusted fully revised IP data appearing to have a structural break (around 1970) - first available IP data do not appear to have a structural break. Interestingly, though, non-benchmark revisions for both NSA and SA IP data do exhibit evidence of a structural break. In particular, the mean non-benchmark revision is considerably smaller in the latter part of the sample (post 1976 for NSA data and post 1972 for SA data), suggesting that data collection and processing methods have become more efficient over time. ${ }^{7}$ In summary, there is evidence in favor of structural breaks not only in first available and fully revised data, but also in the revision processes of our time series (i.e. see the structural break test rejection probabilities in the 4th column of entries in Tables 1 and 2). This suggests that there may be structural breaks that need to be accounted for when testing for unbiasedness and efficiency.

Third, the mean fixed-width, increasing width, and remaining revisions for industrial production are often significantly different from zero (as denoted by superscripts $\mathrm{a}, \mathrm{b}$, and c, referring to $1 \%, 5 \%$, and $10 \%$ significance level rejections of the null hypothesis that the mean revision is zero). As might be expected, there are fewer significant entries in the PPI tables. For example, for the NSA PPI, only the $3^{\text {rd }}$ and $4^{\text {th }}$ fixed-width revision means are significantly different from zero, which is due to the fact that most observations are revised only once, four months after initial publication.

Fourth, there is rather overwhelming evidence of structural breaks in the volatility of first available data, fully revised data, and revision data. Furthermore, based on the structural break dates given in the tables, it is clear that the volatility of

\footnotetext{
${ }^{7}$ We shall see that the evidence in favor of structural breaks in the IP data is also strong when revisions are used to form unbiasedness and efficiency test regressions.
} 
preliminary announcements and final growth rates of all series has declined substantially since the 1980s, suggesting that preliminary announcements have become more precise over time, and providing further evidence that data collection and reporting methods have improved over time. ${ }^{8}$

Fifth, with regard to business cycle nonlinearity, notice that inflation is higher and industrial production growth negative (and larger in absolute magnitude) during recessionary periods than during expansionary periods (see the last three columns of the tables). Thus, the stylized fact that recessions are shorter in duration, but greater in intensity is borne out in our data sets. We find no compelling evidence for business cycle asymmetry in the mean revision for any of the series under consideration, however. Hence, it does not appear that reporting agencies are overly conservative during expansions or liberal during recessions when reporting preliminary IP data, for example. Notice, though, that for both NSA and SA IP, the hypothesis of equality of the mean of the first fixed-width revision during expansions and recessions is close to being rejected. Furthermore, during recessions the IP growth rate is adjusted downward initially, as on average the first fixed-width revision is negative. This implies that the second release of IP actually is further away from the final data than the first release. This is not the case during expansions. Thus, while there is little evidence of business cycle asymmetry in the means of the revision series during expansions and recessions, there is evidence of other types of interesting business cycle asymmetries in the data revision, and hence data reporting processes.

Sixth, there is strong evidence in the IP series that there are business cycle asymmetries in the volatility, not only for first available and fully revised data but also for revisions. For example, the differential between volatilities in the complete non-benchmark revision of both NSA and SA IP data during expansionary and recessionary phases is $27 \%$, with volatility being larger during recessions. This finding suggests that uncertainty is different during different phases of the business cycle, and that this difference in uncertainty has an effect on the reliability of preliminary and early releases of IP data. Put another way, while the precision of first releases of data may not change on average (recall that the evidence for nonlinearity is substantially weaker for mean revisions), the volatility of revisions does depend on whether we are in recession or expansion. In the sense that the volatility of revisions measures the ability of reporting agencies to effectively gather information, we thus

\footnotetext{
${ }^{8}$ For SA IP data, the structural change is dated in 1984, in agreement with McConnell and Perez-Quiros (2000) and others, who report that the volatility of quarterly GDP has declined since around that time.
} 
have evidence that they have more difficulty during bad times. This suggests that the stylized fact that there is more volatility during bad times extends to statistical reporting agencies as well. Many explanations for this feature of the data exist, and a number of them are discussed above. ${ }^{9}$

Seventh, note from Tables 1-4 that the volatility of ${ }_{t+1} X_{t}$ is substantially less than that of ${ }_{f} X_{t}$ for IP. This finding is not consistent with the errors in variables model outlined in Mankiw et al. (1984). On the other hand, the opposite holds when PPI data are examined, suggesting that the errors-in-variables model is a candidate for describing PPI data. Additional support for the above arguments can be made by noting that the correlation between the total revision and ${ }_{f} X_{t}$ is is around 0.40 for SA and NSA IP, while it is close to zero for SA and NSA PPI (see Table 5). Even though this suggests that the two types of data are very different, we shall later see that they still have much in common.

Finally, note that Table 5 contains simple correlations which are useful for ascertaining the relationship between the various types of data that we have available in our real-time data sets. In particular, correlations between fully revised, fully revised but corrected for benchmark revisions (FRCBR), and first available (FA) data, the complete revision (CR), non-benchmark revision (NBR), and benchmark revision $(\mathrm{BR})$ in the series are given. Two conclusions which can be drawn from this table are noteworthy. First, seasonally unadjusted first available data are much more highly correlated with their fully revised counterparts than the corresponding seasonally adjusted data. Thus, the seasonal adjustment process itself, which is highly nonlinear (see e.g. Ghysels, Granger and Siklos (1996)) seems to weaken the linkage between first available and final data. Second, regardless as to whether the data have been seasonally adjusted, the correlations of both first available and fully revised data with the revisions themselves are often far from zero and are both positive and negative (correlations in excess of $25 \%$ are not uncommon, for example).

Overall, the main conclusion from these tables that carries through to the rest of our analysis is that there are often substantial revisions to the data, and that we should test for both structural breaks and business cycle asymmetry when fitting unbiasedness and efficiency regression models.

\footnotetext{
${ }^{9}$ It is worth noting that non-benchmark revision volatility in IP is larger during recessions until the $2^{\text {nd }}$ or $3^{\text {rd }}$ data release. For later releases, this situation is reversed, and there is more uncertainty regarding the remaining revision during expansions.
} 


\subsection{Unbiasedness and Efficiency}

In the following subsections, we discuss results based on unbiasedness and efficiency regression models of the form given in (4), (6), and (8). For unbiasedness tests, we always set $\gamma=0$ in the regression models. Additionally, we consider three different types of efficiency tests, namely: (i) Type I: set $W_{t+k}={ }_{t+k} X_{t}-{ }_{t+1} X_{t}$, that is, only include the revision between the first and $k^{\text {th }}$ release of data in order to focus on the forecastibility of the revision process from its own past; Type II: set $W_{t+k}=$ ${ }_{t+k} X_{t}-{ }_{t+1} X_{t}$, the 3 -month Treasury bill rate, the spread between yields on 10 year Treasury bonds and 3-month T-bills, the spread between Baa and Aaa rated corporate bonds, the first difference of logged crude oil prices, and the dividend reinvested return on the $\mathrm{S} \& \mathrm{P} 500$, all measured at the end of month $t+k-1$; and (iii) Type III: set $W_{t+k}$ as in the previous regression, except with all variables measured at the end of calendar month $t$. Notice that our Type II efficiency tests are useful for ascertaining whether we could have formed better $k^{\text {th }}$ releases by using all data available in real-time, that is at $t+k$. On the other hand, Type III efficiency tests keep the variables in $W_{t+k}$ fixed to be available at time $t+1$, regardless of the value of $k$. Thus, these types of tests allow us to determine the length of time needed before all useful information available at the time of first release is incorporated into the revised data.

In all three types of efficiency regressions, we include a set of centered seasonal dummies, that is, we include $\sum_{s=1}^{11} \delta_{s} D_{s, t}^{*}$, where $D_{s, t}^{*}=D_{s, t}-D_{12, t}$, with $D_{s, t}=1$ if time period $t$ corresponds to month $s$ and $D_{s, t}=0$ otherwise. Note that the coefficient $\delta_{s}$ measures the difference between the intercept in month $s$ and the average intercept, $\alpha$. The seasonal effect for December can be computed as $\delta_{12}=$ $-\sum_{s=1}^{11} \delta_{s}$. Hence, by construction, $\sum_{s=1}^{12} \delta_{s}=0$. As a measure of the importance of seasonal effects, we thus report $\delta^{*} \equiv \sqrt{\sum_{s=1}^{12} \hat{\delta}_{s}^{2}}$ in the Tables. ${ }^{10}$

\subsubsection{Linear Models - Unbiasedness}

The basic test of unbiasedness involves testing the null hypothesis $\mathrm{H}_{0}: \alpha=\beta=0$ in (4), while imposing the restriction that $\gamma=0$. In this setup, no structural breaks or business cycle asymmetries are accounted for. Probability values for the corresponding Wald test statistics are given in the third last column of entries in Tables 6 and 7. Based on a rejection probability value of 0.10 (which is used in all

\footnotetext{
${ }^{10}$ Results for the case where seasonal dummies are included in the unbiasedness regressions do not yield qualitatively different results from those reported here, and are available upon request from the authors.
} 
subsequent discussions), for NSA industrial production we see that there is bias in the $1^{\text {st }}$ through $3^{\text {rd }}$ releases of data, and none thereafter. Thus, reporting agencies tend to get it right, on average, after the first three revisions. The bias in SA industrial production persists much longer (i.e. approximately 12 months). This is an interesting feature of the seasonal adjustment process, suggesting that adjustment is sufficiently complex that it takes a full year before bias is removed from data releases. One reason for this may be the very nature of the seasonal adjustment process. In particular, two-sided moving average filters are used, with one side using historical data, and one side using as yet to be determined future data. If the filters place enough weight on data that are not known for a full year or more, this would then account for the increase in bias. In summary, while it is known that preliminary data are often biased, we now have evidence that the bias remains prevalent for multiple months of new releases, and for a year or more with SA data. This suggests that if one's objective is to use timely unbiased data, then unadjusted data is preferable (see e.g. Kavajecz and Collins (1995) for an extensive discussion of this topic). Even more interesting, note that unadjusted PPI is essentially unbiased across all releases, except the $4^{\text {th }}$ for reasons explained above. However, seasonally adjusted PPI is biased at all releases, up to 12 months. Thus, even a full year of revisions is not sufficient to render the seasonally adjusted PPI unbiased estimates of the final data. This is a rather surprising result and casts substantial suspicion on SA price data. ${ }^{11}$

The structural change and nonlinearity (business cycle asymmetry) tests reported in the final two columns of the tables suggest that there is a structural break in the revision process for SA PPI in 1981, regardless of which release $(k)$ of data is used to form the revision. On the other hand, there is no evidence of structural breaks in the adjusted IP data, and all evidence of structural breaks is for early releases of IP and PPI when unadjusted data are examined. Finally, the nonlinearity tests reported in the last column of the tables provide moderate evidence of business cycle asymmetry for unadjusted IP, strong evidence for adjusted IP, moderate evidence for NSA PPI, and no evidence for SA PPI. ${ }^{12}$

\footnotetext{
${ }^{11}$ Notice also that many of the bias regression models have serially correlated and conditionally heteroskedastic errors, according to Breusch-Godfrey serial correlation and autoregressive conditional heteroskedasticity $(\mathrm{ARCH})$ tests reported in the $6^{\text {th }}$ and $7^{\text {th }}$ columns of the tables. This suggests that regression coefficients may be biased and that the regression models may be misspecified, a problem which persists even when $W_{t+k}$ is added to the list of explanatory variables used in the rationality regression models.

${ }^{12}$ Interestingly, there is no evidence of business cycle asymmetry in the NSA PPI regressions when $k=1$ (i.e. based on the use of preliminary data in the unbiasedness regressions). Rather, business
} 


\subsubsection{Linear Models: Efficiency}

The chart of tables given above lists the linear efficiency model tables. In these tables, efficiency test results are contained in the $11^{\text {th }}$ column (tests of the hypothesis that $\gamma=0$ in (4)) and the $13^{\text {th }}$ column (tests of the hypothesis that $\alpha=\beta=\gamma=\delta=0$ in (4)). ${ }^{13}$ Given that we already have results on the unbiasedness of our data, let us focus for now on the joint hypothesis of unbiasedness and efficiency (i.e. the hypothesis that $\alpha=\beta=\gamma=\delta=0$ ). For this hypothesis, early releases of unadjusted IP become efficient after 3 months, regardless of which efficiency test is used, while efficiency is realized for adjusted IP data after 3-4 months. Recall, though, that when only biasedness is tested for, the SA data remain biased even after data have been revised 12 times. This is true, even though no further irrationality is found to be due to missing information after 3-4 months. ${ }^{14}$

The above finding that it takes approximately 3 months before unadjusted IP data are not only unbiased but also efficient suggests that another sort of rationality test could be performed, by checking how many releases of IP data have an impact on returns in the stock market, say. If more than 3 releases have an impact, then that would suggest that agents are irrational, in the sense that they need not have used additional releases of IP when forming their expectations, as earlier releases were already fully rational. An assessment of rationality based on this argument is left for future research.

Interestingly, NSA price data also become efficient after 3-4 data releases, while adjusted price data are only efficient after 12 months. As type I efficiency tests only include as an extra variable the quantity ${ }_{t+k} X_{t}-{ }_{t+1} X_{t}$, we have evidence that the revision process itself is useful. This finding is similar to our findings based on IP, where the past revision ${ }_{t+k} X_{t}-{ }_{t+1} X_{t}$ is useful for explaining the future revision for both adjusted and unadjusted data. Additionally, for all series, inefficiency remains prevalent for a longer period of time when the information set used to check for efficiency includes additional regressors (i.e. when we move from running Type I efficiency regressions to Types II and III). Clearly, then, the revision processes of our price and IP data share some common features, even though the first available and fully revised PPI data conform to the errors in variables model outlined in

cycle asymmetry only becomes apparent after the preliminary data have been revised once (which from our above discussion we know happens after an interval of approximately 4 months).

${ }^{13}$ When testing for seasonality alone (see the $12^{\text {th }}$ column in the linear efficiency tables) revisions from SA data appear to exhibit seasonality.

${ }^{14}$ The reason for this finding may be that $W_{t+k}$ enters into the regression models linearly, while the seasonal adjustment filter applied to the unadjusted data is highly nonlinear. 
Mankiw et al. (1984), while the IP data do not, as discussed above.

Notice also from these tables that there is substantial evidence of both structural breaks and asymmetric business cycle effects in all series. For seasonally unadjusted IP, these features appear to have occurred only for the first few releases, but for the remaining variables test rejections also occur for later releases. This suggests that it may be of interest to re-fit many of our bias and efficiency models with imposed structural breaks and business cycle asymmetry. This is done in the remaining tables. In particular, whenever there is a value of $k$, say $k^{*}$, for which structural change or business cycle asymmetry is present in the linear unbiasedness and/or efficiency regressions reported in Tables 6 -11, all regressions with $k<=k^{*}$ are rerun. This allows us to ascertain whether any of our linear unbiasedness and efficiency findings are dependent on the fact that nonlinearities which are clearly present in the data have not been properly modelled.

\subsubsection{Nonlinearity I: Structural Change Models - Unbiasedness}

In Table 12, notice that for $k=1,2$ (i.e. for those values of $k$ for which we found evidence of structural breaks in the linear unbiasedness regression), when separately testing unbiasedness of early NSA IP releases before and after the structural break, which for most releases is estimated to have occurred in the second half of the 1970s, the data remain biased. However, an interesting feature of the data arises when we examine the results for $k=3,6$, and $12 .{ }^{15}$ In particular, there is a clear improvement in the quality of the data at higher releases in the post-break periods. This finding stems from the observation that the unbiasedness null hypothesis is rejected prebreak, while the data are clearly unbiased post-break. Thus, unbiasedness findings for $k=3,6$, and 12 in the linear model are driven by strong unbiasedness in the post-break period. This sort of picture emerges with all of our series, and whenever either unbiasedness or efficiency regressions are run, pointing to the dangers involved with simply fitting linear models without first testing for nonlinearity. Additionally, this feature of the data is consistent with our earlier finding that early releases of data have become more accurate over time, suggesting that those responsible for constructing early releases of IP are getting it right!

Interestingly, upon examination of both SA and NSA PPI data (see Table 13), many releases of data that are unbiased prior to the break date (1986 for NSA data

\footnotetext{
${ }^{15}$ Even though no evidence of structural change was found for these values of $k$, we still re-ran these regressions with structural change dates picked using the methods discussed above in order to illustrate an interesting feature of the data.
} 
and 1981 for SA data), are biased thereafter.

\subsubsection{Nonlinearity I: Structural Change Models - Efficiency}

For those releases of data where structural breaks were found, imposing these structural breaks does little to change the efficiency test results reported above, although the same sort of asymmetry noted above for unbiasedness pre- and post-break also holds when efficiency rgeressions are re-run allowing for structural breaks.

\subsubsection{Nonlinearity II: Business Cycle Asymmetry Models - Unbiased- ness}

Tables 16 and 17 contain unbiasedness test results for IP and PPI based on models with imposed business cycle asymmetry of the variety discussed in Section 2. For IP, the results in Table 16 exhibit an interesting pattern. In particular, there is more bias across SA releases during expansionary than during recessionary episodes (see the last two columns of each table, where probabilities that there is no bias are given, with the last column corresponding to recessionary periods and the second last corresponding to exansionary periods). (Overall, though, this feature of the data does not appear to characterize the other variables.) At first blush, this finding for SA IP may appear to contradict our previous finding that there is more uncertainty and increased volatility during recessionary periods. However, this is not the case. Recall that our basic statistics included no unbiasedness tests, but instead considered mean revisions during the different stages of the business cycle. Additionally, we previously found strong evidence of increased uncertainty of early data releases during recessions. This does not preclude our current observation that SA IP is more biased during expansions, although the result is nevertheless surprising, and counter to all of our prior evidence on business cycle effects.

\subsubsection{Nonlinearity II: Business Cycle Asymmetry Models - Efficiency}

Notice that the results of the nonlinear efficiency tests reported in Tables 18 and 19 are broadly supportive of the results based on our tests in the linear model. However, one business cycle asymmetry is worth noting. For SA IP, when comparing results from the column with header $\alpha_{1}=\beta_{1}=\gamma_{1}=\delta_{1}=0$ (expansionary episodes) with those from the column with header $\alpha_{2}=\beta_{2}=\gamma_{2}=\delta_{2}=0$ (recessionary episodes), note that data remain inefficient during recessions for 12 months, while they become efficient after at most 6 months during expansions. 


\section{Concluding Remarks}

In this paper we examine the entire revision process for a number of economic variables. This allows us to construct tests of rationality not only for preliminary data (as is done elsewhere), but also for later releases of data. In addition, various features of the revision process itself, which hitherto have not been discussed, can be examined when the entire revision history is available, allowing us to address numerous questions about revision accuracy, volatility, and timing.

Our findings suggest that unadjusted IP and PPI data releases become rational after around 3 months, and so are only temporarily irrational. However, seasonally adjusted data remain irrational for at least twelve months. In addition, unbiasedness and inefficiency are usually removed from the data after around the same number of releases.

For most of the variables examined, we find evidence of predictability of the revision process, either from its own past or from other publicly available information, suggesting a possible route for improving the reporting of preliminary data. We further find evidence of both structural breaks and business cycle nonlinearities, and find that failure to account for these features of the data in some cases leads to incorrect conclusions concerning unbiasedness and efficiency. Finally, there is a clear increase in revision volatility during recessions, suggesting that early data are less reliable in tougher economic times.

A number of issues remain for future research. For example, it remains to assess, in real-time, whether the revision history of a variable can be used to sharpen future preliminary releases of that variable. Faust, Rogers and Wright (2000) have already made important progress in this area by examining preliminary and final GDP data for the G-7 countries, and find some evidence that it can indeed be done, albeit not for US data. Additionally, it should prove of interest to ascertain whether the revision history of one economic variable is useful for predicting other variables, in real-time, as we currently only have in-sample regression based evidence on this matter. 


\section{References}

Amato, J. and N.R. Swanson (2001), The Real-Time Predictive Content of Money for Output, Journal of Monetary Economics 48, 3-24.

Andrews, D.W.K. (1993), Tests for Parameter Instability and Structural Change with Unknown Change Point, Econometrica 61, 821-856.

Bernanke, B.S. and J. Boivin (2001), Monetary Policy in a Data-Rich Environment, Journal of Monetary Economics, forthcoming.

Blanchard, O.J. and J. Simon (2001), The Long and Large Decline in US Output Volatility, Brooking Papers on Economic Activity, 135-174.

Boschen, J.F. and H.I. Grossman (1982), Tests of Equilibrium Macroeconomics Using Contemporaneous Monetary Data, Journal of Monetary Economics 10, 309-333.

Brodsky, N. and P. Newbold (1994), Late Forecasts and Early Revisions of United States GNP, International Journal of Forecasting 10, 455-460.

Burns, A.F. and W.C. Mitchell (1946), Measuring Business Cycles, New York: NBER.

Campbell, B. and E. Ghysels (1995), Is the Outcome of the Federal Budget Process Unbiased and Efficient? A Nonparametric Assessment, Review of Economics and Statistics 77, 17-31.

Chauvet, M. and S.M. Potter (2001), Recent Changes in the U.S. Business Cycle, The Manchester School, forthcoming.

Chauvet, M. and J.T. Guo (2001), Sunspots, Animal Spirits, and Economic Fluctuations, Macroeconomic Dynamics, forthcoming.

Croushore, D. and T. Stark (2001), A Real-Time Dataset for Macroeconomists, Journal of Econometrics, forthcoming.

Diebold, F.X. and G.D. Rudebusch (1991), Forecasting Output with the Composite Leading Index: A Real-Time Analysis, Journal of the American Statistical Association 86, 603-610.

Diebold, F.X. and G.D. Rudebusch (1996), Measuring Business Cycles: A Modern Perspective, Review of Economics and Statistics 78, 67-77.

Engle, R.F. and C.W.J. Granger (1987), Co-integration and Error-Correction: Representation, Estimation and Testing, Econometrica 55, 251-276.

Faust, J., J.H. Rogers and J.H. Wright (2000), News and Noise in G-7 GDP Announcements, Federal Reserve Board, International Finance Discussion Papers \# 690.

Gallo, G.M. and M. Marcellino (1999), Ex Post and Ex Ante Analysis of Provisional Data, Journal of Forecasting 18, 421-433.

Ghysels, E., C.W.J. Granger and P. Siklos (1996), Is Seasonal Adjustment a Linear or Nonlinear Data-Filtering Transformation, Journal of Business and Economic Statistics 14, 374-386.

Granger, C.W.J. (2001), An Overview of Nonlinear Macroeconometric Empirical Models, Macroeconomic Dynamics 5, forthcoming. 
Hamilton, J.D. and G. Perez-Quiros (1996), What Do the Leading Indicators Lead?, Journal of Business 69, 27-49.

Hansen, B. (2000), Testing For Structural Change in Conditional Models, Journal of Econometrics 97, 93-115.

Howrey, E.P. (1978), The Use of Preliminary Data in Econometric Forecasting, Review of Economics and Statistics 66, 386-393.

Kahn, J., M.M. McConnell and G. Perez Quiros (2001), The Reduced Volatility of the US Economy: Policy or Progress?, mimeo, Federal Reserve Bank of New York.

Kavajecz, K.A. and S. Collins (1995), Rationality of Preliminary Money Stock Estimates, Review of Economics and Statistics 77, 32-41.

Keane, M.P. and D.E. Runkle (1989), Are Economic Forecasts Rational?, Federal Reserve Bank of Minneapolis Quarterly Review 13, 26-33.

Keane, M.P. and D.E. Runkle (1990), Testing the Rationality of Price Forecasts: New Evidence from Panel Data, American Economic Review 80, 714-735.

Kennedy, J. (1993), An Analysis of Revisions to the Industrial Production Index, Applied Economics 25, 213-219.

King R.G. and M.W. Watson (1996), Money, Prices, Interest Rates and the Business Cycle, Review of Economics and Statistics 78, 35-53.

Mankiw, N.G., D.E. Runkle and M.D. Shapiro (1984), Are Preliminary Announcements of the Money Stock Rational Forecasts?, Journal of Monetary Economics 14, 15-27.

Mankiw, N.G. and M.D. Shapiro (1986), News or Noise: an Analysis of GNP Revisions, Survey of Current Business 66, 20-25.

Mariano, R.S. and H. Tanizaki (1995), Prediction of Final Data with Use of Preliminary and/or Revised Data, Journal of Forecasting 14, 351-380.

McConnell, M.M. and G. Perez Quiros (2000), Output Fluctuations in the United States: What Has Changed Since the Early 1980s?, American Economic Review 90, 1464-1476.

Milbourne, R.D. and G.W. Smith (1989), How Informative Are Preliminary Announcements of the Money Stock in Canada?, Canadian Journal of Economics, 22, 595-606.

Morgenstern, O. (1963), On The Accuracy of Economic Observations, 2nd. ed., Princeton: Princeton University Press.

Mork, K.A. (1987), Ain't Behavin': Forecast Errors and Measurement Errors in Early GNP Estimates, Journal of Business \& Economic Statistics 5, 165-175.

Muth J.F. (1961), Rational Expectations and the Theory of Price Movements, Econometrica 29, 315-335.

Neftçi, S.N. and Theodossiou (1991), Properties and Stochastic Nature of BEA's Early Estimates of GNP, Journal of Economics and Business 43, 231-239.

Pierce, D.A. (1981), Sources of Error in Economic Time Series, Journal of Econometrics 17, 305-321.

Ramey, V.A. (1991), Nonconvex Costs and the Behavior of Inventories, Journal of Political 
Economy 99, 306-334.

Ramsey J.B. and P. Rothman (1996), Time Irreversibility and Business Cycle Asymmetry, Journal of Money, Credit and Banking 28, 1-21.

Rathjens, P. and R.P. Robins (1995), Do Government Agencies Use Public Data? The Case of GNP, Review of Economics and Statistics 77, 170-172.

Robertson, J.C. and E.W. Tallman (1998), Data Vintages and Measuring Forecast Performance, Federal Reserve Bank of Atlanta Economic Review, Fourth Quarter, 4-20.

Sensier, M. and D. van Dijk (2001), Short-term Volatility Versus Long-term Growth: Evidence in US Macroeconomic Time Series, Centre for Growth and Business Cycle Research Discussion Paper No. 8, University of Manchester.

Shapiro, M.D. and M.W. Watson (1988), Sources of Business-Cycle Fluctuations, NBER Macroeconomics Annual 3, 111-148.

Stekler, H.O. (1967), Data Revisions and Economic Forecasting, Journal of the American Statistical Association 62, 470-483.

Stock, J.H. and M.W. Watson (1996), Evidence on Structural Instability in Macroeconomic Time Series Relations, Journal of Business \& Economic Statistics 14, 11-30.

Stock, J.H. and M.W. Watson (1999), Business Cycle Fluctuations in US Macroeconomic Time Series, in J.B. Taylor and M. Woodford (eds.), Handbook of Macroeconomics Vol. 1A, Amsterdam: Elsevier Science, pp. 3-64.

Swanson, N.R., E. Ghysels and M. Callan (1999), A Multivariate Time Series Analysis of the Data Revision Process for Industrial Production and the Composite Leading Indicator, in R.F. Engle and H. White (eds.), Cointegration, Causality, and Forecasting: A Festschrift in Honour of Clive W.J. Granger, Oxford: Oxford University Press, pp. $45-75$.

Watson, M.W. (1994), Business Cycle Durations and Postwar Stabilization of the US Economy, American Economic Review 84, 24-46.

Zarnowitz, V. (1978), Accuracy and Properties of Recent Macroeconomic Forecasts, American Economic Review 68, 313-319. 
Table 1: Structural Change and Nonlinearity in Mean and Volatility: RealTime Seasonally Unadjusted Industrial Production

\begin{tabular}{|c|c|c|c|c|c|c|c|c|}
\hline & \multirow[b]{2}{*}{$\mu$} & \multicolumn{4}{|c|}{ Structural Change } & \multicolumn{3}{|c|}{ Nonlinearity } \\
\hline & & $\mu_{1}$ & $\mu_{2}$ & $\mu_{1}=\mu_{2}$ & $\tau_{B}$ & $\mu_{1}$ & $\mu_{2}$ & $\mu_{1}=\mu_{2}$ \\
\hline Fully revised & $3.377^{a}$ & $7.488^{a}$ & $2.635^{a}$ & 0.257 & 1968.6 & $5.069^{a}$ & $-7.755^{b}$ & 0.000 \\
\hline First available & $1.932^{b}$ & $4.255^{a}$ & 1.421 & 0.723 & 1969.6 & $3.593^{a}$ & $-8.995^{a}$ & 0.000 \\
\hline Complete revision & $1.444^{a}$ & $3.083^{a}$ & $0.871^{a}$ & 0.080 & 1972.4 & $1.475^{a}$ & 1.240 & 0.879 \\
\hline Non-benchmark revision & $1.116^{a}$ & $2.107^{a}$ & $0.515^{b}$ & 0.006 & 1976.7 & $1.264^{a}$ & 0.139 & 0.104 \\
\hline Benchmark revision & 0.328 & 0.129 & $1.455^{a}$ & 0.388 & 1993.7 & 0.211 & 1.101 & 0.451 \\
\hline \multicolumn{9}{|c|}{ Fixed width (non-benchmark) revisions $t+k+1 X_{t}-{ }_{t+k} X_{t}$} \\
\hline$k=1$ & $0.289^{c}$ & $1.341^{a}$ & -0.048 & 0.009 & 1971.9 & $0.413^{b}$ & -0.523 & 0.153 \\
\hline$k=2$ & $0.469^{a}$ & $0.637^{a}$ & 0.042 & 0.078 & 1988.10 & $0.465^{a}$ & $0.496^{c}$ & 0.934 \\
\hline$k=3$ & $0.318^{a}$ & $0.475^{a}$ & $0.191^{b}$ & 0.405 & 1979.2 & $0.334^{a}$ & 0.215 & 0.614 \\
\hline \multicolumn{9}{|c|}{ Increasing width (non-benchmark) revisions $t+k+1 X_{t}-{ }_{t+1} X_{t}$} \\
\hline$k=1$ & $0.289^{c}$ & $1.341^{a}$ & -0.048 & 0.009 & 1971.9 & $0.413^{b}$ & -0.523 & 0.153 \\
\hline$k=2$ & $0.759^{a}$ & $2.073^{a}$ & $0.509^{b}$ & 0.050 & 1968.9 & $0.878^{a}$ & -0.026 & 0.158 \\
\hline$k=3$ & $1.077^{a}$ & $1.898^{a}$ & $0.603^{b}$ & 0.038 & 1976.2 & $1.212^{a}$ & 0.188 & 0.126 \\
\hline$k=6$ & $1.061^{a}$ & $1.977^{a}$ & $0.534^{b}$ & 0.014 & 1976.2 & $1.196^{a}$ & 0.174 & 0.129 \\
\hline$k=12$ & $1.067^{a}$ & $2.005^{a}$ & $0.526^{b}$ & 0.013 & 1976.2 & $1.203^{a}$ & 0.174 & 0.127 \\
\hline \multicolumn{9}{|c|}{ Remaining (non-benchmark) revisions ${ }_{f} X_{t}-{ }_{t+k} X_{t}$} \\
\hline$k=1$ & $1.116^{a}$ & $2.107^{a}$ & $0.515^{b}$ & 0.006 & 1976.7 & $1.264^{a}$ & 0.139 & 0.104 \\
\hline$k=2$ & $0.827^{a}$ & $1.160^{a}$ & $0.369^{b}$ & 0.116 & 1983.10 & $0.852^{a}$ & 0.662 & 0.676 \\
\hline$k=3$ & $0.357^{a}$ & $0.671^{a}$ & 0.099 & 0.040 & 1979.3 & $0.386^{a}$ & 0.166 & 0.408 \\
\hline$k=6$ & $0.066^{c}$ & $0.235^{a}$ & -0.042 & 0.140 & 1977.1 & $0.080^{c}$ & -0.022 & 0.178 \\
\hline$k=12$ & $0.066^{c}$ & $0.151^{a}$ & -0.054 & 0.107 & 1984.1 & $0.081^{b}$ & -0.035 & 0.089 \\
\hline \multirow[t]{3}{*}{$k=24$} & 0.011 & $0.055^{c}$ & -0.050 & 0.618 & 1984.1 & 0.013 & 0.000 & 0.600 \\
\hline & & \multicolumn{4}{|c|}{ Structural Change } & \multicolumn{3}{|c|}{ Nonlinearity } \\
\hline & $\sigma$ & $\sigma_{1}$ & $\sigma_{2}$ & $\sigma_{1}=\sigma_{2}$ & $\tau_{B}$ & $\sigma_{1}$ & $\sigma_{2}$ & $\sigma_{1}=\sigma_{2}$ \\
\hline Fully revised & 29.792 & 34.021 & 25.678 & 0.005 & 1980.9 & 28.955 & 35.299 & 0.082 \\
\hline First available & 28.034 & 29.415 & 23.198 & 0.152 & 1990.12 & 27.315 & 32.765 & 0.111 \\
\hline Complete revision & 10.356 & 11.001 & 8.373 & 0.047 & 1990.2 & 10.009 & 12.638 & 0.093 \\
\hline Non-benchmark revision & 5.597 & 6.604 & 3.357 & 0.000 & 1987.10 & 5.395 & 6.924 & 0.072 \\
\hline Benchmark revision & 8.079 & 7.287 & 8.828 & 0.150 & 1980.6 & 8.002 & 8.583 & 0.613 \\
\hline \multicolumn{9}{|c|}{ Fixed width (non-benchmark) revisions $t+k+1 X_{t}-{ }_{t+k} X_{t}$} \\
\hline$k=1$ & 3.414 & 4.448 & 2.864 & 0.000 & 1975.6 & 3.265 & 4.391 & 0.004 \\
\hline$k=2$ & 2.744 & 3.094 & 1.965 & 0.000 & 1987.10 & 2.597 & 3.710 & 0.004 \\
\hline$k=3$ & 1.424 & 0.858 & 1.532 & 0.002 & 1968.9 & 1.348 & 1.925 & 0.010 \\
\hline \multicolumn{9}{|c|}{ Increasing width (non-benchmark) revisions $t+k+1 X_{t}-{ }_{t+1} X_{t}$} \\
\hline$k=1$ & 3.414 & 4.448 & 2.864 & 0.000 & 1975.6 & 3.265 & 4.391 & 0.004 \\
\hline$k=2$ & 4.888 & 5.651 & 3.191 & 0.000 & 1987.10 & 4.688 & 6.201 & 0.032 \\
\hline$k=\overline{3}$ & 5.233 & 6.079 & 3.352 & 0.000 & 1987.10 & 5.027 & 6.586 & 0.051 \\
\hline$k=6$ & 5.292 & 6.170 & 3.340 & 0.000 & 1987.10 & 5.083 & 6.671 & 0.060 \\
\hline$k=12$ & 5.381 & 6.294 & 3.351 & 0.000 & 1987.10 & 5.185 & 6.672 & 0.078 \\
\hline \multicolumn{9}{|c|}{ Remaining (non-benchmark) revisions ${ }_{f} X_{t}-{ }_{t+k} X_{t}$} \\
\hline$k=1$ & 5.597 & 6.604 & 3.357 & 0.000 & 1987.10 & 5.395 & 6.924 & 0.072 \\
\hline$k=2$ & 3.700 & 4.339 & 2.279 & 0.000 & 1987.10 & 3.506 & 4.978 & 0.015 \\
\hline$k=3$ & 1.947 & 2.228 & 1.425 & 0.000 & 1986.5 & 1.908 & 2.203 & 0.291 \\
\hline$k=6$ & 0.829 & 1.206 & 0.150 & 0.000 & 1986.2 & 0.897 & 0.384 & 0.012 \\
\hline$k=12$ & 0.559 & 0.835 & 0.090 & 0.000 & 1985.8 & 0.583 & 0.400 & 0.351 \\
\hline$k=24$ & 0.173 & 0.278 & 0.014 & 0.003 & 1984.8 & 0.197 & 0.014 & 0.005 \\
\hline
\end{tabular}

Notes: The table contains results from tests of structural change, nonlinearity in the mean and nonlinearity in variance of real-time data on annualized monthly growth rates of seasonally unadjusted Industrial Production over the period 1963.1-1998.12, based on data vintages for 1963.1-2001.1. In the upper block, the column headed $\mu$ contains the unconditional mean, the columns headed $\mu_{1}$ and $\mu_{2}$ under "Structural Change" contain the means before and after the break-point $\tau_{B}$, which is determined by maximizing the point-wise heteroskedasticity- and autocorrelation-consistent Wald test for testing $\mathrm{H}_{0}: \mu_{1}=\mu_{2}$. The $p$ value corresponding to the null hypothesis that there was no structural break in the mean of the process is reported in the column headed $\mu_{1}=\mu_{2}$. The columns headed $\mu_{1}$ and $\mu_{2}$ under "Nonlinearity" contain the means during expansions and recessions, respectively, which are defined according to NBER business cycle turning points. The column headed $\mu_{1}=\mu_{2}$ contains the $p$-value for the Wald test of equality of these two means. Entries marked with ${ }^{a},{ }^{b}$ and ${ }^{c}$ are significantly different from zero at the 1, 5 and $10 \%$ level, respectively, using HAC standard errors. The lower block of the table contains similar statistics for the standard deviations of the time series (computed under the assumption of a constant mean). 
Table 2: Structural Change and Nonlinearity in Mean and Volatility: RealTime Seasonally Adjusted Industrial Production

\begin{tabular}{|c|c|c|c|c|c|c|c|c|}
\hline & \multirow[b]{2}{*}{$\mu$} & \multicolumn{4}{|c|}{ Structural Change } & \multicolumn{3}{|c|}{ Nonlinearity } \\
\hline & & $\mu_{1}$ & $\mu_{2}$ & $\mu_{1}=\mu_{2}$ & $\tau_{B}$ & $\mu_{1}$ & $\mu_{2}$ & $\mu_{1}=\mu_{2}$ \\
\hline Fully revised & $3.358^{a}$ & $6.547^{a}$ & $2.688^{a}$ & 0.034 & 1969.3 & $5.241^{a}$ & $-9.029^{a}$ & 0.000 \\
\hline First available & $2.163^{a}$ & $4.477^{a}$ & $1.646^{b}$ & 0.270 & 1969.7 & $4.047^{a}$ & $-10.232^{a}$ & 0.000 \\
\hline Complete revision & $1.195^{a}$ & $2.182^{a}$ & $0.815^{b}$ & 0.185 & 1972.12 & $1.193^{a}$ & 1.204 & 0.992 \\
\hline Non-benchmark revision & $0.927^{a}$ & $1.599^{a}$ & $0.674^{a}$ & 0.075 & 1972.10 & $1.029^{a}$ & 0.254 & 0.126 \\
\hline Benchmark revision & 0.268 & 0.071 & $1.027^{a}$ & 0.206 & 1991.7 & 0.165 & 0.949 & 0.413 \\
\hline \multicolumn{9}{|c|}{ Fixed width (non-benchmark) revisions $t+k+1 X_{t}-{ }_{t+k} X_{t}$} \\
\hline$k=1$ & $0.178^{c}$ & $0.457^{a}$ & 0.099 & 0.476 & 1970.12 & $0.236^{b}$ & -0.203 & 0.186 \\
\hline$k=2$ & $0.360^{a}$ & $0.531^{a}$ & 0.128 & 0.162 & 1983.9 & $0.359^{a}$ & $0.365^{c}$ & 0.980 \\
\hline$k=3$ & $0.313^{a}$ & $0.436^{a}$ & $0.267^{a}$ & 0.795 & 1972.10 & $0.338^{a}$ & 0.148 & 0.190 \\
\hline \multicolumn{9}{|c|}{ Increasing width (non-benchmark) revisions ${ }_{t+k+1} X_{t}-{ }_{t+1} X_{t}$} \\
\hline$k=1$ & $0.178^{c}$ & $0.457^{a}$ & 0.099 & 0.476 & 1970.12 & $0.236^{b}$ & -0.203 & 0.186 \\
\hline$k=2$ & $0.539^{a}$ & $0.655^{a}$ & -0.086 & 0.040 & 1993.4 & $0.596^{a}$ & 0.162 & 0.286 \\
\hline$k=3$ & $0.852^{a}$ & $0.968^{a}$ & 0.227 & 0.098 & 1993.4 & $0.934^{a}$ & 0.310 & 0.158 \\
\hline$k=6$ & $0.875^{a}$ & $1.429^{a}$ & $0.666^{a}$ & 0.114 & 1972.10 & $0.960^{a}$ & 0.311 & 0.144 \\
\hline$k=12$ & $0.858^{a}$ & $1.371^{a}$ & $0.656^{a}$ & 0.112 & 1973.2 & $0.941^{a}$ & 0.311 & 0.156 \\
\hline \multicolumn{9}{|c|}{ Remaining (non-benchmark) revisions ${ }_{f} X_{t}-{ }_{t+k} X_{t}$} \\
\hline$k=1$ & $0.927^{a}$ & $1.599^{a+}$ & $0.674^{a}$ & 0.075 & 1972.10 & $1.029^{a}$ & 0.254 & 0.126 \\
\hline$k=2$ & $0.748^{a}$ & $1.238^{a}$ & $0.466^{a}$ & 0.139 & 1976.2 & $0.793^{a}$ & 0.457 & 0.322 \\
\hline$k=3$ & $0.388^{a}$ & $0.773^{a}$ & $0.238^{a}$ & 0.443 & 1973.1 & $0.433^{a}$ & 0.092 & 0.137 \\
\hline$k=6$ & 0.091 & $0.267^{c}$ & -0.022 & 0.527 & 1977.1 & 0.109 & -0.029 & 0.309 \\
\hline$k=12$ & 0.067 & $0.228^{c}$ & -0.037 & 0.222 & 1977.1 & 0.086 & -0.056 & 0.303 \\
\hline \multirow[t]{3}{*}{$k=24$} & 0.001 & 0.100 & $-0.062^{c}$ & 0.762 & 1977.1 & -0.001 & 0.017 & 0.847 \\
\hline & & \multicolumn{4}{|c|}{ Structural Change } & \multicolumn{3}{|c|}{ Nonlinearity } \\
\hline & $\sigma$ & $\sigma_{1}$ & $\sigma_{2}$ & $\sigma_{1}=\sigma_{2}$ & $\tau_{B}$ & $\sigma_{1}$ & $\sigma_{2}$ & $\sigma_{1}=\sigma_{2}$ \\
\hline Fully revised & 8.785 & 10.629 & 6.127 & 0.000 & 1984.3 & 7.510 & 17.167 & 0.000 \\
\hline First available & 8.014 & 9.879 & 5.300 & 0.000 & 1984.4 & 6.695 & 16.687 & 0.000 \\
\hline Complete revision & 6.208 & 7.019 & 4.404 & 0.000 & 1987.10 & 6.043 & 7.291 & 0.220 \\
\hline Non-benchmark revision & 4.043 & 4.475 & 3.082 & 0.000 & 1987.10 & 3.906 & 4.947 & 0.078 \\
\hline Benchmark revision & 5.090 & 5.873 & 3.810 & 0.000 & 1985.4 & 4.985 & 5.782 & 0.306 \\
\hline \multicolumn{9}{|c|}{ Fixed width (non-benchmark) revisions $t+k+1 X_{t}-{ }_{t+k} X_{t}$} \\
\hline$k=1 \quad$ & 2.016 & 1.573 & 2.154 & 0.032 & 1971.7 & 1.934 & 2.553 & 0.045 \\
\hline$k=2$ & 1.704 & 1.316 & 1.845 & 0.007 & 1972.7 & 1.635 & 2.162 & 0.039 \\
\hline$k=3$ & 0.991 & 0.946 & 1.244 & 0.114 & 1993.7 & 0.994 & 0.968 & 0.834 \\
\hline \multicolumn{9}{|c|}{ Increasing width (non-benchmark) revisions $t+k+1 X_{t}-{ }_{t+1} X_{t}$} \\
\hline$k=1$ & 2.016 & 1.573 & 2.154 & 0.032 & 1971.7 & 1.934 & 2.553 & 0.045 \\
\hline$k=2$ & 3.061 & 2.358 & 3.316 & 0.002 & 1972.7 & 2.925 & 3.951 & 0.051 \\
\hline$k=3$ & 3.396 & 2.728 & 3.677 & 0.009 & 1973.8 & 3.248 & 4.371 & 0.065 \\
\hline$k=6$ & 3.526 & 2.810 & 3.768 & 0.024 & 1972.1 & 3.392 & 4.408 & 0.111 \\
\hline$k=12$ & 3.772 & 4.114 & 3.012 & 0.004 & 1987.10 & 3.676 & 4.406 & 0.252 \\
\hline \multicolumn{9}{|c|}{ Remaining (non-benchmark) revisions ${ }_{f} X_{t}-{ }_{t+k} X_{t}$} \\
\hline$k=1$ & 4.043 & 4.475 & 3.082 & 0.000 & 1987.10 & 3.906 & 4.947 & 0.078 \\
\hline$k=2$ & 2.924 & 3.286 & 2.178 & 0.000 & 1987.3 & 2.888 & 3.163 & 0.460 \\
\hline$k=3$ & 2.071 & 2.392 & 1.415 & 0.000 & 1987.2 & 2.136 & 1.644 & 0.143 \\
\hline$k=6$ & 1.382 & 1.799 & 0.522 & 0.000 & 1987.3 & 1.472 & 0.787 & 0.054 \\
\hline$k=12$ & 1.017 & 1.339 & 0.392 & 0.000 & 1986.9 & 1.055 & 0.767 & 0.406 \\
\hline$k=24$ & 0.457 & 0.843 & 0.193 & 0.000 & 1977.7 & 0.469 & 0.372 & 0.738 \\
\hline
\end{tabular}

Notes: The table contains results from tests for structural change and nonlinearity in the mean and variance of real-time data on annualized monthly growth rates of seasonally adjusted Industrial Production over the period 1963.1-1998.12, based on data vintages for 1963.1-2001.1. See Table 1 for further details. 
Table 3: Structural Change and Nonlinearity in Mean and Volatility: RealTime Seasonally Unadjusted Producer Price Index for Finished Goods

\begin{tabular}{|c|c|c|c|c|c|c|c|c|}
\hline & \multirow[b]{2}{*}{$\mu$} & \multicolumn{4}{|c|}{ Structural Change } & \multicolumn{3}{|c|}{ Nonlinearity } \\
\hline & & $\mu_{1}$ & $\mu_{2}$ & $\mu_{1}=\mu_{2}$ & $\tau_{B}$ & $\mu_{1}$ & $\mu_{2}$ & $\mu_{1}=\mu_{2}$ \\
\hline Fully revised & $3.202^{a}$ & $10.924^{a}$ & $1.782^{a}$ & 0.000 & 1981.4 & $2.928^{a}$ & $5.220^{a}$ & 0.191 \\
\hline First available & $3.200^{a}$ & $10.807^{a}$ & $1.801^{a}$ & 0.000 & 1981.4 & $2.922^{a}$ & $5.252^{a}$ & 0.191 \\
\hline Complete revision & 0.002 & 0.122 & -0.019 & 1.000 & 1981.2 & 0.007 & -0.032 & 0.814 \\
\hline Non-benchmark revision & -0.003 & 0.079 & -0.019 & 1.000 & 1981.5 & -0.002 & -0.013 & 0.940 \\
\hline Benchmark revision & 0.011 & 0.121 & -0.030 & 0.977 & 1980.9 & 0.019 & -0.026 & 0.696 \\
\hline \multicolumn{9}{|c|}{ Fixed width (non-benchmark) revisions $t+k+1 X_{t}-{ }_{t+k} X_{t}$} \\
\hline$k=1$ & -0.002 & -0.005 & 0.000 & 0.993 & 1985.6 & -0.002 & 0.000 & 0.312 \\
\hline$k=3$ & $-0.540^{a}$ & $-1.517^{a}$ & $-0.285^{b}$ & 0.000 & 1982.5 & $-0.454^{a}$ & $-1.178^{b}$ & 0.008 \\
\hline$k=4$ & $0.539^{a}$ & $1.533^{a}$ & $0.285^{b}$ & 0.000 & 1982.4 & $0.465^{a}$ & $1.082^{b}$ & 0.043 \\
\hline \multicolumn{9}{|c|}{ Increasing width (non-benchmark) revisions $t+k+1 X_{t}-{ }_{t+1} X_{t}$} \\
\hline$k=1$ & -0.002 & $\begin{array}{l}t+005 \\
-0.005\end{array}$ & 0.000 & 0.993 & 1985.6 & -0.002 & 0.000 & 0.312 \\
\hline$k=3$ & $-0.542^{a}$ & $-1.517^{a}$ & $-0.287^{a}$ & 0.000 & 1982.5 & $-0.455^{a}$ & $-1.178^{a}$ & 0.008 \\
\hline$k=4$ & -0.003 & 0.094 & -0.021 & 1.000 & 1981.5 & 0.010 & -0.096 & 0.472 \\
\hline$k=6$ & -0.016 & -0.082 & 0.018 & 1.000 & 1985.1 & -0.016 & -0.013 & 0.982 \\
\hline$k=12$ & -0.003 & 0.079 & -0.019 & 1.000 & 1981.5 & -0.002 & -0.013 & 0.940 \\
\hline \multicolumn{9}{|c|}{ Remaining (non-benchmark) revisions ${ }_{f} X_{t}-{ }_{t+k} X_{t}$} \\
\hline$k=1$ & -0.001 & 0.079 & -0.017 & 1.000 & 1981.5 & 0.000 & -0.013 & 0.930 \\
\hline$k=2$ & -0.001 & 0.079 & -0.017 & 1.000 & 1981.5 & 0.000 & -0.013 & 0.930 \\
\hline$k=3$ & $0.539^{a}$ & $1.522^{a}$ & $0.288^{a}$ & 0.001 & 1982.4 & $0.454^{a}$ & $1.166^{a}$ & 0.025 \\
\hline$k=4$ & -0.000 & -0.017 & 0.008 & 1.000 & 1985.1 & -0.011 & 0.083 & 0.228 \\
\hline \multirow[t]{3}{*}{$k=6$} & 0.012 & 0.085 & 0.000 & 0.675 & 1981.2 & 0.014 & 0.000 & 0.148 \\
\hline & & \multicolumn{4}{|c|}{ Structural Change } & \multicolumn{3}{|c|}{ Nonlinearity } \\
\hline & $\sigma$ & $\sigma_{1}$ & $\sigma_{2}$ & $\sigma_{1}=\sigma_{2}$ & $\tau_{B}$ & $\sigma_{1}$ & $\sigma_{2}$ & $\sigma_{1}=\sigma_{2}$ \\
\hline Fully revised & 6.139 & 10.309 & 5.371 & 0.000 & 1981.4 & 5.892 & 7.957 & 0.064 \\
\hline First available & 6.220 & 10.213 & 5.486 & 0.000 & 1981.4 & 5.999 & 7.854 & 0.137 \\
\hline Complete revision & 1.180 & 1.234 & 0.880 & 0.299 & 1995.10 & 1.195 & 1.072 & 0.570 \\
\hline Non-benchmark revision & 1.097 & 0.926 & 1.180 & 0.380 & 1984.11 & 1.132 & 0.841 & 0.114 \\
\hline Benchmark revision & 0.688 & 0.933 & 0.522 & 0.001 & 1982.1 & 0.672 & 0.754 & 0.654 \\
\hline \multicolumn{9}{|c|}{ Fixed width (non-benchmark) revisions $t+k+1 X_{t}-{ }_{t+k} X_{t}$} \\
\hline$k=1$ & 0.004 & 0.008 & 0.002 & 0.825 & 1985.6 & 0.004 & 0.002 & 0.312 \\
\hline$k=3$ & 1.233 & 1.419 & 1.075 & 0.041 & 1987.8 & 1.226 & 1.285 & 0.707 \\
\hline$k=4$ & 1.234 & 1.430 & 1.072 & 0.027 & 1987.7 & 1.237 & 1.215 & 0.910 \\
\hline \multicolumn{9}{|c|}{ Increasing width (non-benchmark) revisions $t+k+1 X_{t}-{ }_{t+1} X_{t}$} \\
\hline$k=1$ & 0.004 & 0.008 & 0.002 & 0.825 & 1985.6 & 0.004 & 0.002 & 0.312 \\
\hline$k=3$ & 1.231 & 1.415 & 1.075 & 0.046 & 1987.8 & 1.224 & 1.285 & 0.700 \\
\hline$k=4$ & 1.090 & 0.929 & 1.171 & 0.421 & 1985.1 & 1.121 & 0.863 & 0.155 \\
\hline$k=6$ & 1.114 & 1.155 & 0.883 & 0.627 & 1995.10 & 1.151 & 0.841 & 0.093 \\
\hline$k=12$ & 1.097 & 0.926 & 1.180 & 0.380 & 1984.11 & 1.132 & 0.841 & 0.114 \\
\hline \multicolumn{9}{|c|}{ Remaining (non-benchmark) revisions ${ }_{f} X_{t}-{ }_{t+k} X_{t}$} \\
\hline$k=1$ & 1.099 & 0.926 & 1.183 & 0.366 & 1984.11 & 1.134 & 0.841 & 0.111 \\
\hline$k=2$ & 1.099 & 0.926 & 1.183 & 0.366 & 1984.11 & 1.134 & 0.841 & 0.111 \\
\hline$k=3$ & 1.264 & 1.497 & 1.071 & 0.005 & 1987.7 & 1.263 & 1.274 & 0.954 \\
\hline$k=4$ & 0.096 & 0.574 & 0.013 & 0.000 & 1981.2 & 0.095 & 0.104 & 0.924 \\
\hline$k=6$ & 0.031 & 0.119 & 0.016 & 0.001 & 1981.2 & 0.033 & 0.016 & 0.148 \\
\hline
\end{tabular}

Notes: The table contains results from tests for structural change and nonlinearity in the mean and variance of real-time data on annualized monthly growth rates of the seasonally unadjusted Producer Price Index for Finished Goods over the period 1978.2-1998.12, based on data vintages for 1978.2-2001.1. For completeness, we planned to include $\mathrm{k}=2$ in all of the panels in the above table, and $\mathrm{k}=12$ to increasing width and remaining revision panels. However, note that these values of $\mathrm{k}$ are still not reported for some types of revisions. The reason for this is that all revisions for these values of $\mathrm{k}$ are identically zero. See Table 1 for further details. 
Table 4: Structural Change and Nonlinearity in Mean and Volatility: RealTime Seasonally Adjusted Producer Price Index for Finished Goods

\begin{tabular}{|c|c|c|c|c|c|c|c|c|}
\hline & \multirow[b]{2}{*}{$\mu$} & \multicolumn{4}{|c|}{ Structural Change } & \multicolumn{3}{|c|}{ Nonlinearity } \\
\hline & & $\mu_{1}$ & $\mu_{2}$ & $\mu_{1}=\mu_{2}$ & $\tau_{B}$ & $\mu_{1}$ & $\mu_{2}$ & $\mu_{1}=\mu_{2}$ \\
\hline Fully revised & $3.209^{a}$ & $10.970^{a}$ & $1.782^{a}$ & 0.000 & 1981.4 & $2.898^{a}$ & $5.500^{a}$ & 0.115 \\
\hline First available & $3.327^{a}$ & $11.317^{a}$ & $1.813^{a}$ & 0.000 & 1981.5 & $3.012^{a}$ & $5.651^{a}$ & 0.153 \\
\hline Complete revision & -0.118 & -0.532 & -0.025 & 0.821 & 1981.11 & -0.114 & -0.151 & 0.932 \\
\hline Non-benchmark revision & -0.016 & -0.062 & 0.122 & 1.000 & 1993.9 & 0.012 & -0.216 & 0.424 \\
\hline Benchmark revision & -0.103 & -0.619 & -0.013 & 0.732 & 1981.2 & -0.125 & 0.065 & 0.459 \\
\hline \multicolumn{9}{|c|}{ Fixed width (non-benchmark) revisions ${ }_{t+k+1} X_{t}-{ }_{t+k} X_{t}$} \\
\hline$k=1$ & 0.020 & $\begin{array}{r}t+\kappa+1 \\
0.011\end{array}$ & $\begin{array}{r}t+k<t \\
0.057\end{array}$ & 1.000 & 1994.11 & 0.020 & 0.014 & 0.833 \\
\hline$k=2$ & -0.024 & -0.060 & 0.002 & 0.746 & 1986.11 & -0.019 & -0.061 & 0.352 \\
\hline$k=3$ & $-0.138^{b}$ & -0.049 & $-0.509^{a}$ & 0.202 & 1994.11 & $-0.158^{b}$ & 0.008 & 0.104 \\
\hline$k=4$ & $0.134^{b}$ & 0.030 & $0.555^{b}$ & 0.126 & 1994.10 & $0.157^{b}$ & -0.035 & 0.287 \\
\hline \multicolumn{9}{|c|}{ Increasing width (non-benchmark) revisions $t+k+1 X_{t}-{ }_{t+1} X_{t}$} \\
\hline$k=1$ & 0.020 & $\begin{array}{l}t+k+1 \\
0.011\end{array}$ & ${ }^{t}{ }^{t}{ }^{t+057}$ & 1.000 & 1994.11 & 0.020 & 0.014 & 0.833 \\
\hline$k=2$ & -0.005 & -0.037 & 0.058 & 0.671 & 1991.11 & 0.001 & -0.046 & 0.378 \\
\hline$k=3$ & $-0.143^{b}$ & -0.061 & $-0.605^{a}$ & 0.192 & 1995.10 & $-0.157^{b}$ & -0.038 & 0.264 \\
\hline$k=4$ & -0.009 & -0.061 & 0.116 & 0.755 & 1992.10 & -0.000 & -0.073 & 0.600 \\
\hline$k=6$ & -0.049 & $-0.146^{b}$ & 0.051 & 0.598 & 1988.8 & -0.022 & -0.242 & 0.241 \\
\hline$k=12$ & 0.001 & 0.097 & -0.062 & 1.000 & 1986.5 & 0.019 & -0.128 & 0.531 \\
\hline \multicolumn{9}{|c|}{ Remaining (non-benchmark) revisions ${ }_{f} X_{t}-{ }_{t+k} X_{t}$} \\
\hline$k=1$ & -0.016 & -0.062 & 0.122 & 1.000 & 1993.9 & 0.012 & -0.216 & 0.424 \\
\hline$k=2$ & -0.035 & -0.073 & 0.076 & 1.000 & 1993.8 & -0.009 & -0.231 & 0.430 \\
\hline$k=3$ & -0.011 & -0.040 & 0.128 & 1.000 & 1995.4 & 0.011 & -0.170 & 0.510 \\
\hline$k=4$ & 0.128 & 0.030 & $0.587^{a}$ & 0.254 & 1995.4 & 0.169 & -0.178 & 0.245 \\
\hline$k=6$ & 0.024 & 0.062 & -0.099 & 0.989 & 1994.1 & 0.030 & -0.017 & 0.831 \\
\hline \multirow[t]{3}{*}{$k=12$} & 0.058 & -0.036 & $0.138^{c}$ & 0.470 & 1987.8 & 0.062 & 0.029 & 0.867 \\
\hline & & \multicolumn{4}{|c|}{ Structural Change } & \multicolumn{3}{|c|}{ Nonlinearity } \\
\hline & $\sigma$ & $\sigma_{1}$ & $\sigma_{2}$ & $\sigma_{1}=\sigma_{2}$ & $\tau_{B}$ & $\sigma_{1}$ & $\sigma_{2}$ & $\sigma_{1}=\sigma_{2}$ \\
\hline Fully revised & 5.113 & 9.823 & 4.247 & 0.000 & 1981.4 & 4.920 & 6.541 & 0.268 \\
\hline First available & 5.723 & 10.477 & 4.848 & 0.000 & 1981.4 & 5.489 & 7.445 & 0.167 \\
\hline Complete revision & 2.357 & 3.491 & 2.116 & 0.000 & 1981.9 & 2.328 & 2.572 & 0.337 \\
\hline Non-benchmark revision & 1.689 & 1.036 & 1.802 & 0.037 & 1981.2 & 1.686 & 1.714 & 0.936 \\
\hline Benchmark revision & 1.741 & 3.260 & 1.478 & 0.000 & 1981.2 & 1.752 & 1.657 & 0.780 \\
\hline \multicolumn{9}{|c|}{ Fixed width (non-benchmark) revisions $t+k+1 X_{t}-{ }_{t+k} X_{t}$} \\
\hline$k=1$ & 0.126 & 0.056 & $\begin{array}{r}t+147 \\
0.14\end{array}$ & 0.756 & 1982.11 & 0.138 & 0.041 & 0.001 \\
\hline$k=2$ & 0.124 & 0.069 & 0.150 & 0.755 & 1984.10 & 0.127 & 0.103 & 0.638 \\
\hline$k=3$ & 0.506 & 0.357 & 1.076 & 0.000 & 1994.8 & 0.533 & 0.305 & 0.025 \\
\hline$k=4$ & 0.533 & 0.385 & 1.089 & 0.000 & 1994.7 & 0.545 & 0.449 & 0.613 \\
\hline \multicolumn{9}{|c|}{ Increasing width (non-benchmark) revisions $t+k+1 X_{t}-{ }_{t+1} X_{t}$} \\
\hline$k=1$ & 0.126 & 0.056 & 0.147 & 0.756 & 1982.11 & 0.138 & 0.041 & 0.001 \\
\hline$k=2$ & 0.204 & 0.077 & 0.241 & 0.452 & 1982.10 & 0.218 & 0.099 & 0.046 \\
\hline$k=3$ & 0.659 & 0.538 & 1.120 & 0.000 & 1994.8 & 0.697 & 0.381 & 0.010 \\
\hline$k=4$ & 0.712 & 0.532 & 1.385 & 0.000 & 1994.7 & 0.734 & 0.548 & 0.501 \\
\hline$k=6$ & 0.914 & 0.698 & 1.229 & 0.007 & 1990.6 & 0.932 & 0.780 & 0.647 \\
\hline$k=12$ & 1.502 & 1.207 & 1.769 & 0.021 & 1987.12 & 1.544 & 1.193 & 0.299 \\
\hline \multicolumn{9}{|c|}{ Remaining (non-benchmark) revisions ${ }_{f} X_{t}-{ }_{t+k} X_{t}$} \\
\hline$k=1$ & 1.689 & 1.036 & 1.802 & 0.037 & 1981.2 & 1.686 & 1.714 & 0.936 \\
\hline$k=2$ & 1.675 & 1.007 & 1.791 & 0.027 & 1981.2 & 1.673 & 1.694 & 0.951 \\
\hline$k=3$ & 1.611 & 1.327 & 1.867 & 0.033 & 1987.12 & 1.609 & 1.622 & 0.969 \\
\hline$k=4$ & 1.590 & 1.384 & 1.776 & 0.217 & 1987.12 & 1.573 & 1.716 & 0.685 \\
\hline$k=6$ & 1.221 & 1.418 & 0.367 & 0.000 & 1995.1 & 1.204 & 1.351 & 0.675 \\
\hline$k=12$ & 0.655 & 0.744 & 0.185 & 0.034 & 1995.8 & 0.598 & 1.073 & 0.202 \\
\hline
\end{tabular}

Notes: The table contains results from tests for structural change and nonlinearity in the mean and variance of real-time data on annualized monthly growth rates of the seasonally adjusted Producer Price Index for Finished Goods over the period 1978.2-1998.12, based on data vintages for 1978.2-2001.1. See Table 1 for further details. 
Table 5: Various Real-Time Data Correlations

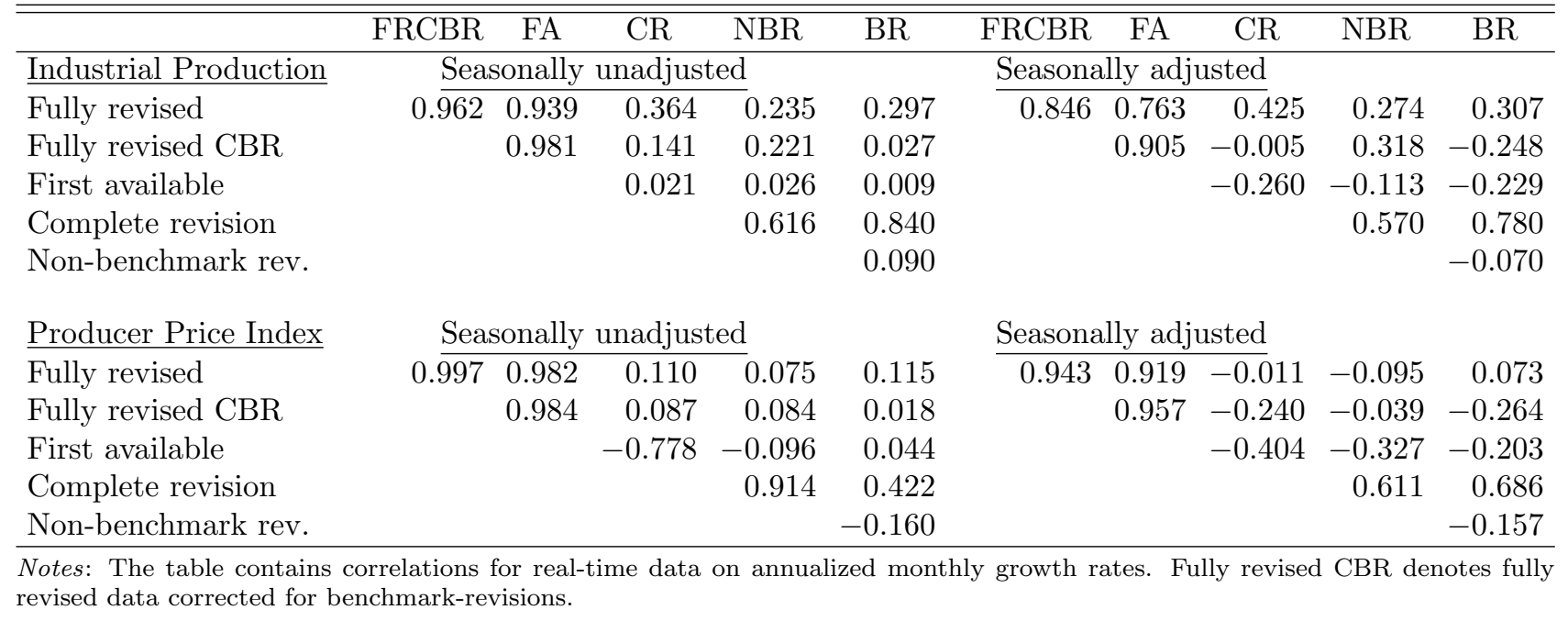


Table 6: Unbiasedness of Real-Time Growth Rates of Industrial Production - Linear Model

\begin{tabular}{|c|c|c|c|c|c|c|c|c|c|c|}
\hline Release $k$ & $\alpha$ & $\beta$ & $\overline{\mathrm{R}}^{2}$ & DW & $\mathrm{BG}(3)$ & $\mathrm{ARCH}(1)$ & LJB & $\begin{array}{l}\alpha=0 \\
\beta=0\end{array}$ & $\begin{array}{c}\mathrm{SC} \\
\left(\tau_{B}\right) \\
\end{array}$ & NL \\
\hline \multicolumn{11}{|c|}{ Seasonally Unadjusted } \\
\hline 1 & $\begin{array}{c}1.106 \\
(0.223)\end{array}$ & $\begin{array}{c}0.005 \\
(0.011)\end{array}$ & -0.002 & 2.296 & 0.002 & 0.019 & 0.545 & 0.000 & $\begin{array}{c}0.000 \\
(1976.2)\end{array}$ & 0.283 \\
\hline 2 & $\begin{array}{c}0.799 \\
(0.160)\end{array}$ & $\begin{array}{c}0.012 \\
(0.007)\end{array}$ & 0.006 & 2.136 & 0.143 & 0.000 & 0.009 & 0.000 & $\begin{array}{c}0.059 \\
(1976.2)\end{array}$ & 0.615 \\
\hline 3 & $\begin{array}{c}0.345 \\
(0.094)\end{array}$ & $\begin{array}{c}0.005 \\
(0.004)\end{array}$ & 0.002 & 2.078 & 0.421 & 0.001 & 0.000 & 0.000 & $\begin{array}{c}0.134 \\
(1979.3)\end{array}$ & 0.070 \\
\hline 4 & $\begin{array}{c}0.046 \\
(0.053)\end{array}$ & $\begin{array}{c}-0.002 \\
(0.003)\end{array}$ & -0.000 & 2.523 & 0.000 & 0.000 & 0.000 & 0.585 & $\begin{array}{c}0.130 \\
(1977.10)\end{array}$ & 0.407 \\
\hline 5 & $\begin{array}{c}0.059 \\
(0.047)\end{array}$ & $\begin{array}{c}-0.003 \\
(0.003)\end{array}$ & 0.001 & 2.547 & 0.000 & 0.000 & 0.000 & 0.361 & $\begin{array}{c}0.162 \\
(1976.2)\end{array}$ & 0.560 \\
\hline 6 & $\begin{array}{c}0.075 \\
(0.045)\end{array}$ & $\begin{array}{c}-0.003 \\
(0.003)\end{array}$ & 0.002 & 2.612 & 0.000 & 0.000 & 0.000 & 0.205 & $\begin{array}{c}0.269 \\
(1977.10)\end{array}$ & 0.229 \\
\hline 12 & $\begin{array}{c}0.068 \\
(0.036)\end{array}$ & $\begin{array}{c}-0.001 \\
(0.002)\end{array}$ & -0.002 & 2.617 & 0.000 & 0.000 & 0.000 & 0.177 & $\begin{array}{c}0.295 \\
(1984.1)\end{array}$ & 0.144 \\
\hline 24 & $\begin{array}{c}0.011 \\
(0.020)\end{array}$ & $\begin{array}{c}0.000 \\
(0.001)\end{array}$ & -0.002 & 2.562 & 0.000 & 0.000 & 0.000 & 0.857 & $\begin{array}{c}0.760 \\
(1984.1)\end{array}$ & 0.857 \\
\hline \multicolumn{11}{|c|}{ Seasonally Adjusted } \\
\hline 1 & $\begin{array}{l}1.038 \\
(0.191)\end{array}$ & $\begin{array}{c}-0.051 \\
(0.025)\end{array}$ & 0.011 & $2 . \overline{002}$ & 0.509 & 0.004 & 0.608 & 0.000 & $\begin{array}{c}0.362 \\
(1976.2)\end{array}$ & 0.002 \\
\hline 2 & $\begin{array}{c}0.781 \\
(0.144)\end{array}$ & $\begin{array}{c}-0.014 \\
(0.018)\end{array}$ & -0.001 & 2.036 & 0.776 & 0.000 & 0.021 & 0.000 & $\begin{array}{c}0.298 \\
(1976.2)\end{array}$ & 0.130 \\
\hline 3 & $\begin{array}{c}0.410 \\
(0.108)\end{array}$ & $\begin{array}{c}-0.008 \\
(0.015)\end{array}$ & -0.001 & 2.255 & 0.040 & 0.000 & 0.000 & 0.001 & $\begin{array}{c}0.518 \\
(1970.1)\end{array}$ & 0.005 \\
\hline 4 & $\begin{array}{c}0.136 \\
(0.083)\end{array}$ & $\begin{array}{c}-0.020 \\
(0.013)\end{array}$ & 0.006 & 2.522 & 0.000 & 0.000 & 0.000 & 0.166 & $\begin{array}{c}0.374 \\
(1968.4)\end{array}$ & 0.021 \\
\hline 5 & $\begin{array}{c}0.150 \\
(0.080)\end{array}$ & $\begin{array}{c}-0.021 \\
(0.012)\end{array}$ & 0.008 & 2.581 & 0.000 & 0.000 & 0.000 & 0.101 & $\begin{array}{c}0.414 \\
(1968.4)\end{array}$ & 0.029 \\
\hline 6 & $\begin{array}{c}0.161 \\
(0.080)\end{array}$ & $\begin{array}{c}-0.023 \\
(0.012)\end{array}$ & 0.011 & 2.610 & 0.000 & 0.000 & 0.000 & 0.073 & $\begin{array}{c}0.362 \\
(1968.4)\end{array}$ & 0.014 \\
\hline 12 & $\begin{array}{c}0.120 \\
(0.068)\end{array}$ & $\begin{array}{c}-0.017 \\
(0.010)\end{array}$ & 0.008 & 2.455 & 0.000 & 0.000 & 0.000 & 0.110 & $\begin{array}{c}0.364 \\
(1968.4)\end{array}$ & 0.022 \\
\hline 24 & $\begin{array}{c}0.036 \\
(0.050)\end{array}$ & $\begin{array}{c}-0.011 \\
(0.007)\end{array}$ & 0.005 & 2.376 & 0.000 & 0.000 & 0.000 & 0.312 & $\begin{array}{c}0.290 \\
(1970.1)\end{array}$ & 0.151 \\
\hline
\end{tabular}

Notes: The table contains unbiasedness test results for different releases of annualized monthly growth rates of Industrial Production over the period 1963.1-1998.12, based on data vintages for 1963.1-2001.1, and based on estimating equation (4) with $\gamma=0$ imposed. Acronyms appearing in the table include: DW=Durbin-Watson statistic, BG(3) $=$ BrueschGodfrey LM test of no residual autocorrelation up to order 3, $\mathrm{ARCH}(1)=\mathrm{LM}$ test for first-order ARCH effects, and LJB = Lomnicki-Jarque-Bera test for normality of the regression residuals. All entries in these columns, except DW, are $p$-values. The column headed $\alpha=0 \beta=0$, contains the $p$-value of the Wald statistic for testing the indicated restriction. The column headed SC contains the $p$-value from the sup-Wald test for testing the hypothesis $\mathrm{H}_{0}: \alpha_{1}=\alpha_{2}$ and $\beta_{1}=\beta_{2}$ in equation (8) with $\gamma_{1}=\gamma_{2}=0$ imposed, where the change-point, $\tau_{B}$, is given in parentheses. The column headed SC contains the $p$-value from the Wald test for testing the hypothesis $\mathrm{H}_{0}: \alpha_{1}=\alpha_{2}$ and $\beta_{1}=\beta_{2}$ in equation (6) with $\gamma_{1}=\gamma_{2}=0$ imposed, using NBER-defined recessions and expansions. For all test statistics, heteroskedasticity and autocorrelation-consistent versions are used. Additionally, heteroskedasticity and autocorrelation-consistent standard errors are given in parentheses under coefficient estimates. 
Table 7: Unbiasedness of Real-Time Growth Rates of the Producer Price Index for Finished Goods - Linear Model

\begin{tabular}{|c|c|c|c|c|c|c|c|c|c|c|}
\hline Release $k$ & $\alpha$ & $\beta$ & $\overline{\mathrm{R}}^{2}$ & DW & $\mathrm{BG}(3)$ & $\operatorname{ARCH}(1)$ & LJB & $\begin{array}{l}\alpha=0 \\
\beta=0\end{array}$ & $\begin{array}{c}\mathrm{SC} \\
\left(\tau_{B}\right)\end{array}$ & NL \\
\hline \multicolumn{11}{|c|}{ Seasonally Unadjusted } \\
\hline 1 & $\begin{array}{c}0.052 \\
(0.055)\end{array}$ & $\begin{array}{c}-0.017 \\
(0.011)\end{array}$ & 0.005 & 2.710 & 0.000 & 0.219 & 0.001 & 0.305 & $\begin{array}{c}0.083 \\
(1986.2)\end{array}$ & 0.832 \\
\hline 2 & $\begin{array}{c}0.055 \\
(0.055)\end{array}$ & $\begin{array}{c}-0.018 \\
(0.011)\end{array}$ & 0.005 & 2.711 & 0.000 & 0.223 & 0.002 & 0.295 & $\begin{array}{c}0.002 \\
(1986.2)\end{array}$ & 0.830 \\
\hline 3 & $\begin{array}{c}0.055 \\
(0.055)\end{array}$ & $\begin{array}{c}-0.018 \\
(0.011)\end{array}$ & 0.005 & 2.711 & 0.000 & 0.223 & 0.002 & 0.295 & $\begin{array}{c}0.002 \\
(1986.2)\end{array}$ & 0.830 \\
\hline 4 & $\begin{array}{c}0.499 \\
(0.131)\end{array}$ & $\begin{array}{c}0.015 \\
(0.017)\end{array}$ & 0.001 & 0.988 & 0.000 & 0.000 & 0.020 & 0.000 & $\begin{array}{c}0.000 \\
(1982.4)\end{array}$ & 0.025 \\
\hline 5 & $\begin{array}{c}0.008 \\
(0.010)\end{array}$ & $\begin{array}{c}-0.003 \\
(0.003)\end{array}$ & -0.002 & 2.518 & 0.000 & 0.000 & 0.000 & 0.388 & $\begin{array}{c}0.860 \\
(1981.2)\end{array}$ & 0.185 \\
\hline 6 & $\begin{array}{c}0.011 \\
(0.007)\end{array}$ & $\begin{array}{c}0.000 \\
(0.003)\end{array}$ & -0.004 & 2.247 & 0.021 & 0.120 & 0.000 & 0.266 & $\begin{array}{c}0.718 \\
(1981.2)\end{array}$ & 0.264 \\
\hline \multicolumn{11}{|c|}{ Seasonally Adjusted } \\
\hline 1 & $\begin{array}{c}0.301 \\
(0.106)\end{array}$ & $\begin{array}{c}-0.095 \\
(0.021)\end{array}$ & 0.104 & $2 . \overline{354}$ & 0.001 & 0.882 & 0.693 & 0.000 & $\begin{array}{c}0.000 \\
(1981.4)\end{array}$ & 0.854 \\
\hline 2 & $\begin{array}{c}0.287 \\
(0.102)\end{array}$ & $\begin{array}{c}-0.096 \\
(0.021)\end{array}$ & 0.109 & 2.360 & 0.003 & 0.978 & 0.529 & 0.000 & $\begin{array}{c}0.000 \\
(1981.4)\end{array}$ & 0.871 \\
\hline 3 & $\begin{array}{c}0.291 \\
(0.099)\end{array}$ & $\begin{array}{c}-0.091 \\
(0.020)\end{array}$ & 0.101 & 2.450 & 0.000 & 0.610 & 0.247 & 0.000 & $\begin{array}{c}0.000 \\
(1981.4)\end{array}$ & 0.791 \\
\hline 4 & $\begin{array}{c}0.386 \\
(0.108)\end{array}$ & $\begin{array}{c}-0.081 \\
(0.022)\end{array}$ & 0.082 & 2.195 & 0.009 & 0.435 & 0.182 & 0.000 & $\begin{array}{c}0.000 \\
(1981.4)\end{array}$ & 0.584 \\
\hline 5 & $\begin{array}{c}0.207 \\
(0.097)\end{array}$ & $\begin{array}{c}-0.065 \\
(0.018)\end{array}$ & 0.062 & 2.336 & 0.010 & 0.651 & 0.000 & 0.002 & $\begin{array}{c}0.000 \\
(1981.6)\end{array}$ & 0.874 \\
\hline 6 & $\begin{array}{c}0.229 \\
(0.092)\end{array}$ & $\begin{array}{c}-0.062 \\
(0.017)\end{array}$ & 0.060 & 2.299 & 0.021 & 0.613 & 0.000 & 0.001 & $\begin{array}{c}0.000 \\
(1981.6)\end{array}$ & 0.859 \\
\hline 12 & $\begin{array}{c}0.173 \\
(0.070)\end{array}$ & $\begin{array}{c}-0.035 \\
(0.012)\end{array}$ & 0.039 & 2.253 & 0.177 & 0.014 & 0.000 & 0.010 & $\begin{array}{c}0.012 \\
(1981.8)\end{array}$ & 0.599 \\
\hline
\end{tabular}

Notes: The table contains unbiasedness test results for different releases of annualized monthly growth rates of the Producer Price Index for Finished Goods over the period 1978.2-1998.12, based on data vintages for 1978.2-2001.1. Note that $\mathrm{k}=12$ is not added to the top panel because revisions are in this case equal to zero for all observations. For the same reason, $\mathrm{k}=12$ is not added to the results in Table 10 below. See Table 6 for further details. 


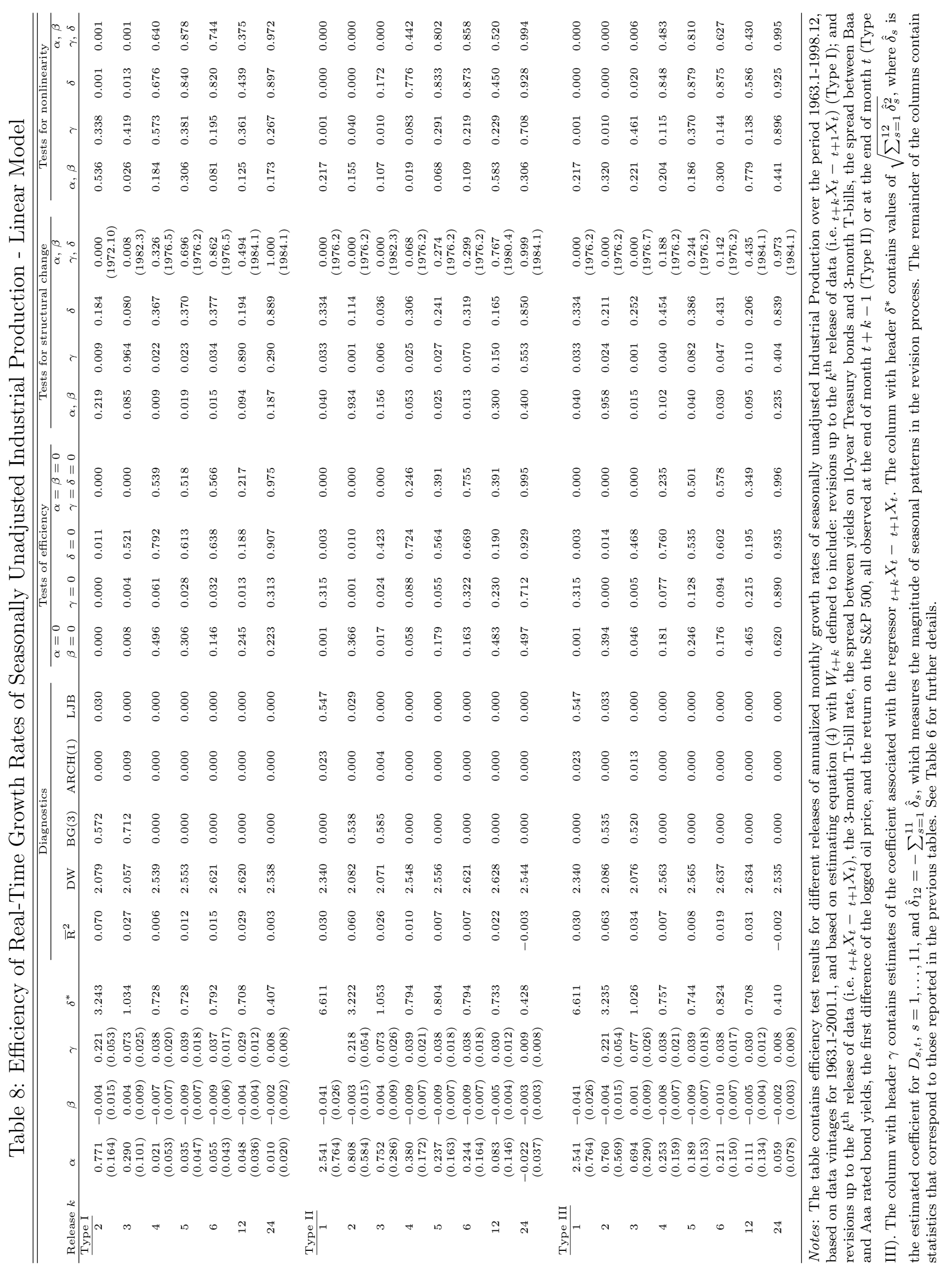




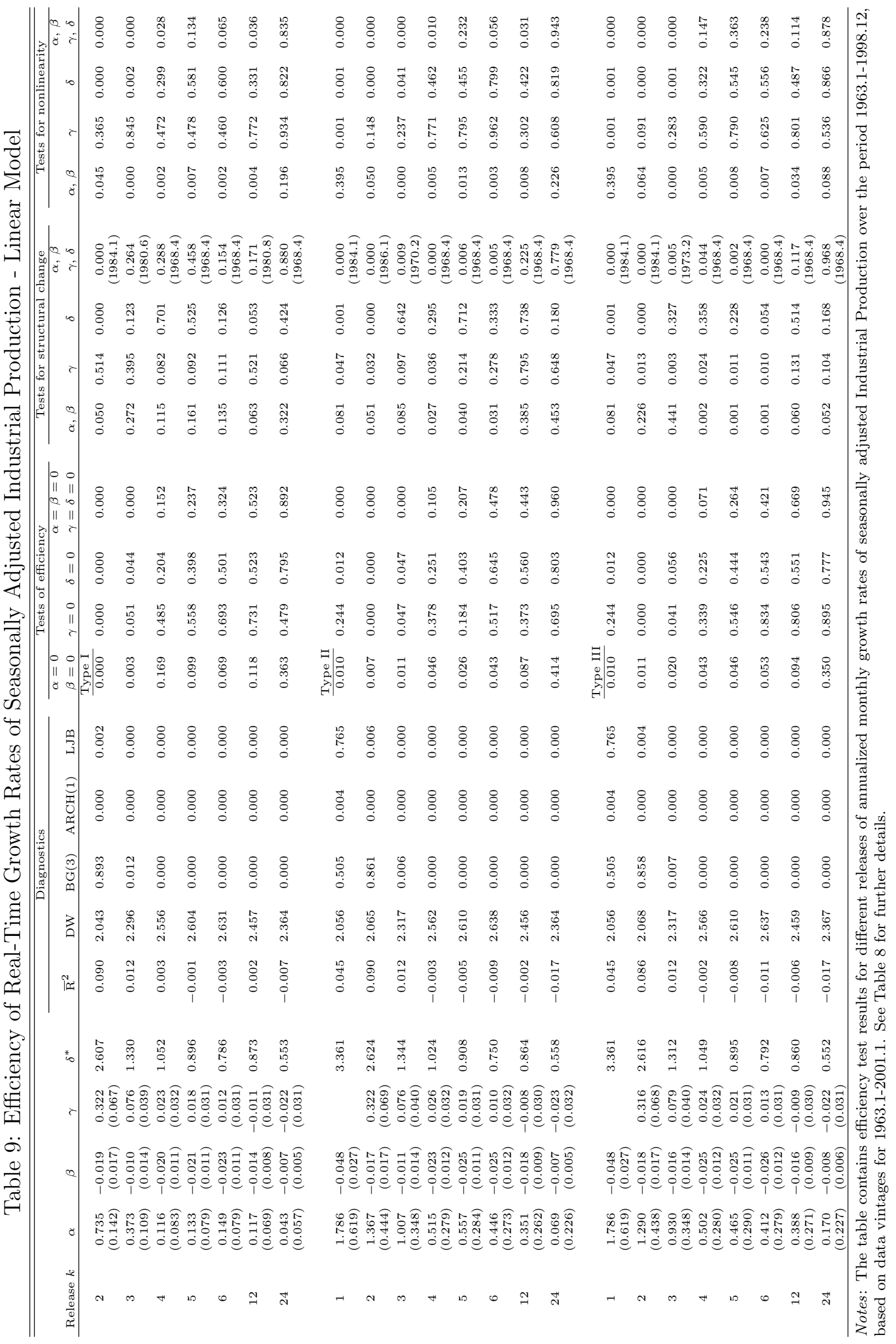




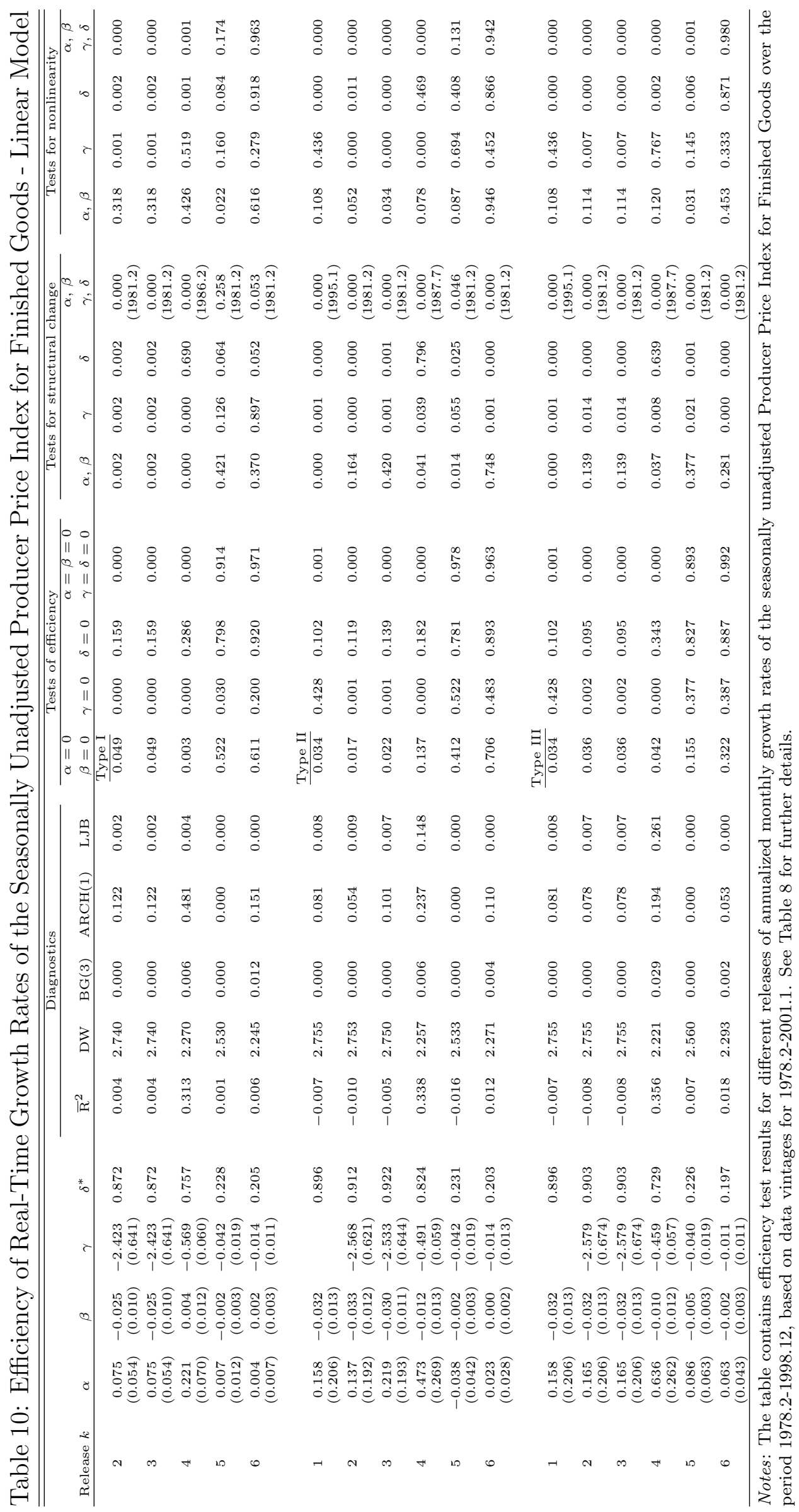




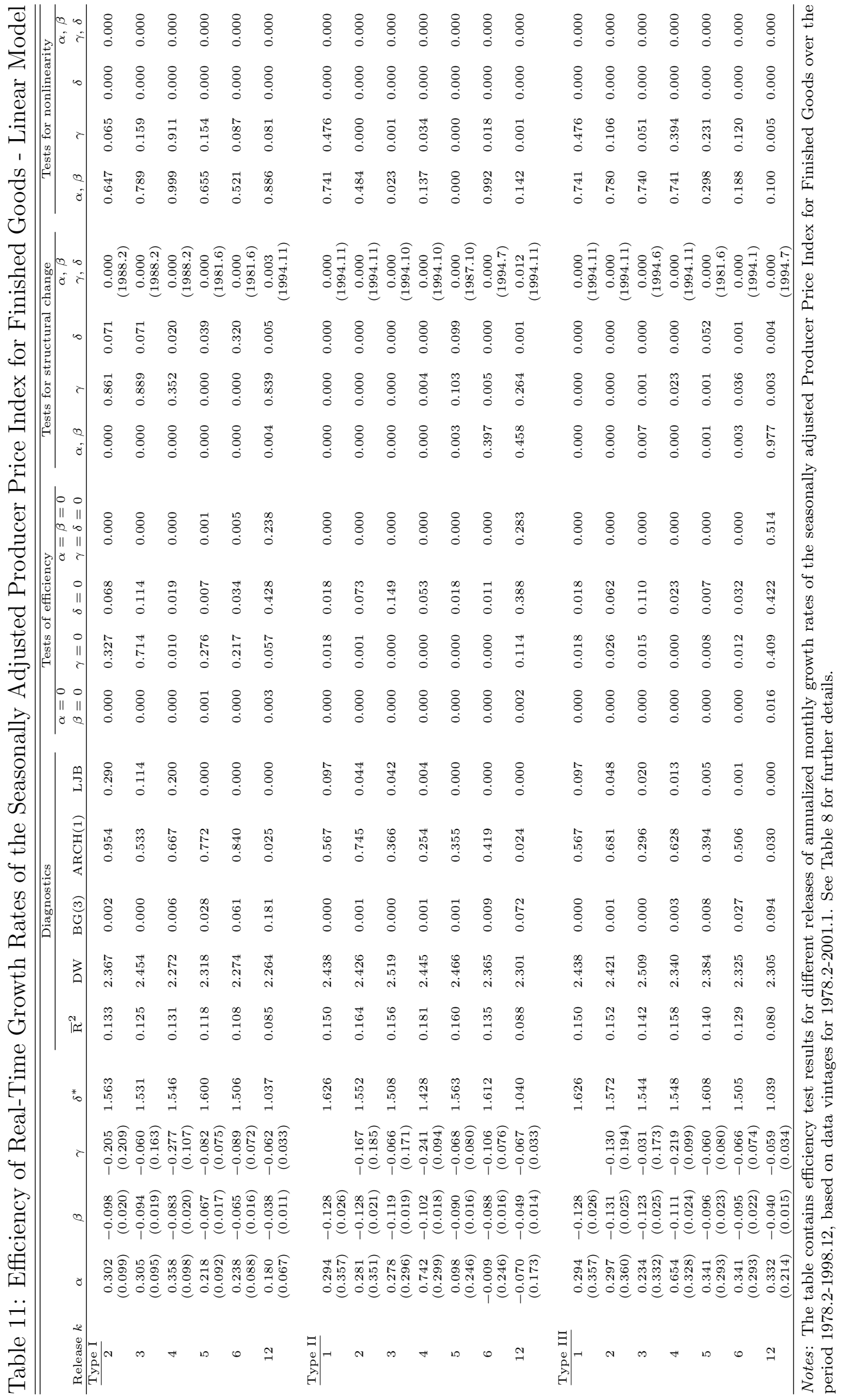


Table 12: Unbiasedness of Real-Time Growth Rates of Industrial Production - Structural Change Model

\begin{tabular}{|c|c|c|c|c|c|c|c|}
\hline Release $k$ & $\alpha_{1}$ & $\beta_{1}$ & $\alpha_{2}$ & $\beta_{2}$ & $\begin{array}{l}\alpha_{1}=\alpha_{2}=0 \\
\beta_{1}=\beta_{2}=0\end{array}$ & $\begin{array}{l}\alpha_{1}=0 \\
\beta_{1}=0\end{array}$ & $\begin{array}{l}\alpha_{2}=0 \\
\beta_{2}=0\end{array}$ \\
\hline \multicolumn{8}{|c|}{ Seasonally Unadjusted } \\
\hline 1 & $\begin{array}{c}2.039 \\
(0.359)\end{array}$ & $\begin{array}{c}0.055 \\
(0.017)\end{array}$ & $\begin{array}{c}0.591 \\
(0.256)\end{array}$ & $\begin{array}{c}-0.027 \\
(0.011)\end{array}$ & 0.000 & 0.000 & 0.007 \\
\hline 2 & $\begin{array}{l}1.268 \\
(0.316)\end{array}$ & $\begin{array}{c}0.030 \\
(0.011)\end{array}$ & $\begin{array}{c}0.532 \\
(0.170)\end{array}$ & $\begin{array}{c}-0.001 \\
(0.009)\end{array}$ & 0.000 & 0.000 & 0.006 \\
\hline 3 & $\begin{array}{c}0.663 \\
(0.158)\end{array}$ & $\begin{array}{c}0.002 \\
(0.006)\end{array}$ & $\begin{array}{c}0.086 \\
(0.101)\end{array}$ & $\begin{array}{c}0.007 \\
(0.005)\end{array}$ & 0.000 & 0.000 & 0.259 \\
\hline 6 & $\begin{array}{c}0.221 \\
(0.089)\end{array}$ & $\begin{array}{c}-0.007 \\
(0.006)\end{array}$ & $\begin{array}{c}-0.025 \\
(0.038)\end{array}$ & $\begin{array}{c}0.001 \\
(0.002)\end{array}$ & 0.138 & 0.040 & 0.769 \\
\hline 12 & $\begin{array}{c}0.149 \\
(0.056)\end{array}$ & $\begin{array}{c}0.000 \\
(0.003)\end{array}$ & $\begin{array}{c}-0.046 \\
(0.042)\end{array}$ & $\begin{array}{c}-0.003 \\
(0.003)\end{array}$ & 0.101 & 0.027 & 0.491 \\
\hline
\end{tabular}

There are no cases where the SC model was found to be useful.

Notes: The table contains unbiasedness test results for different releases of annualized monthly growth rates of Industrial Production over the period 1963.1-1998.12, based on data vintages for 1963.1-2001.1, and based on estimating equation (8) with $\gamma_{1}=\gamma_{2}=0$ imposed. The difference between these results and those reported in Tables 6 and 7 is that equation (8) imposes nonlinearity in the form of structural change on the unbiasedness test regression, while linearity is imposed when equation (4) is estimated (i.e. in Tables 6 and 7). See Table 6 for further details. 
Table 13: Unbiasedness of Real-Time Growth Rates of the Producer Price Index for Finished Goods - Structural Change Model

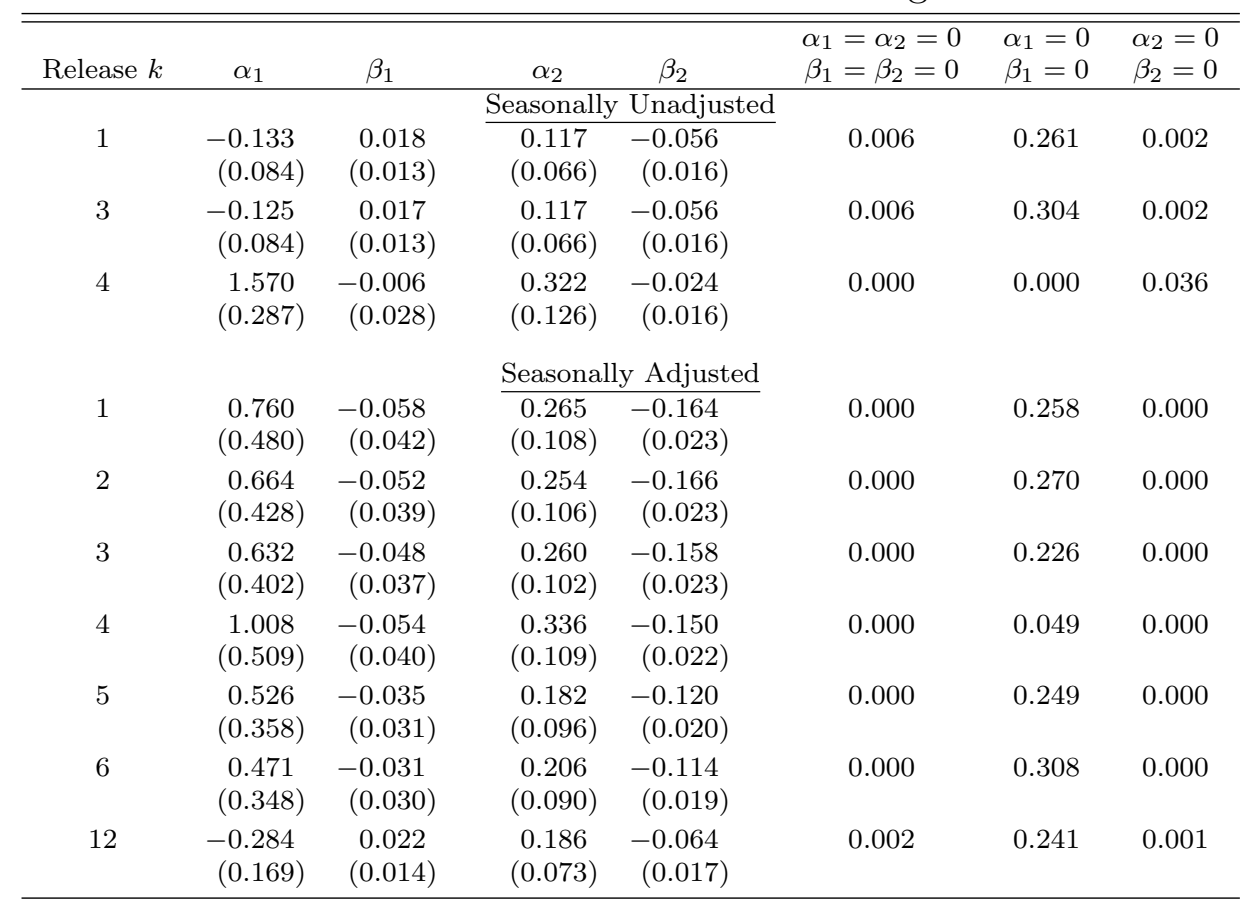

Notes: The table contains unbiasedness test results for different releases of annualized monthly growth rates of the Producer Price Index for Finished Goods over the period 1978.2-1998.12, based on data vintages for 1978.2-2001.1. Note that $\mathrm{k}=2$ has not been added to the top panel of the table because this case yields identical results to those for the $k=3$ case. See Table 12 for further details. 


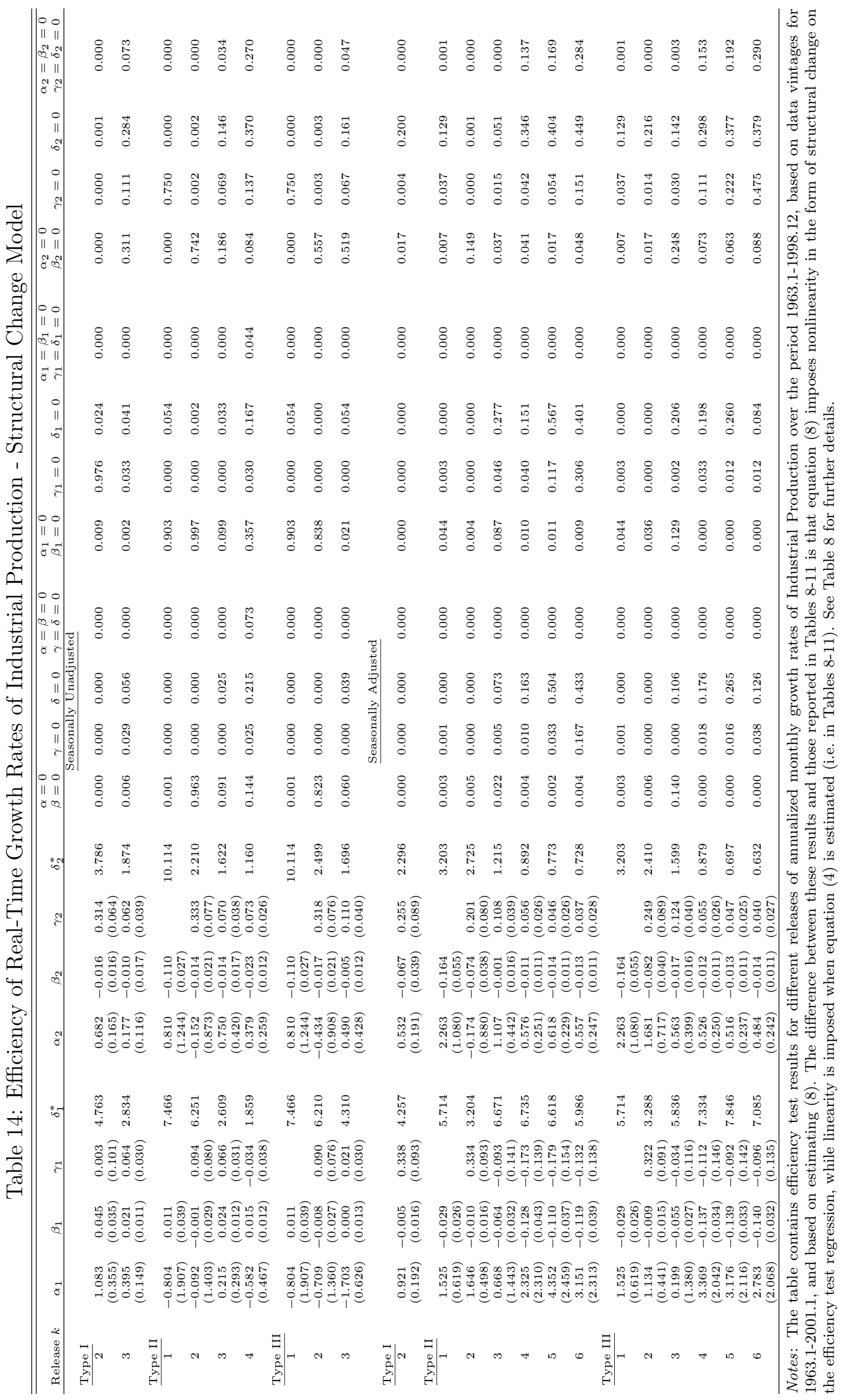


Table 16: Unbiasedness of Real-Time Growth Rates of Industrial Production - NL Business Cycle Model

\begin{tabular}{|c|c|c|c|c|c|c|c|}
\hline Release $k$ & $\alpha_{1}$ & $\beta_{1}$ & $\alpha_{2}$ & $\beta_{2}$ & $\begin{array}{l}\alpha_{1}=\alpha_{2}=0 \\
\beta_{1}=\beta_{2}=0\end{array}$ & $\begin{array}{l}\alpha_{1}=0 \\
\beta_{1}=0\end{array}$ & $\begin{array}{l}\alpha_{2}=0 \\
\beta_{2}=0\end{array}$ \\
\hline 1 & $\begin{array}{l}1.263 \\
(0.241)\end{array}$ & $\begin{array}{c}0.000 \\
(0.012)\end{array}$ & $\begin{array}{c}\text { Seasonally } \\
0.295 \\
(0.631)\end{array}$ & $\begin{array}{c}\text { Unadjusted } \\
0.017 \\
(0.031)\end{array}$ & 0.000 & 0.000 & 0.805 \\
\hline 2 & $\begin{array}{c}0.813 \\
(0.172)\end{array}$ & $\begin{array}{c}0.010 \\
(0.008)\end{array}$ & $\begin{array}{c}0.909 \\
(0.394)\end{array}$ & $\begin{array}{l}0.026 \\
(0.015)\end{array}$ & 0.000 & 0.000 & 0.011 \\
\hline 3 & $\begin{array}{c}0.380 \\
(0.104)\end{array}$ & $\begin{array}{c}0.001 \\
(0.005)\end{array}$ & $\begin{array}{c}0.340 \\
(0.229)\end{array}$ & $\begin{array}{c}0.019 \\
(0.006)\end{array}$ & 0.000 & 0.001 & 0.003 \\
\hline 1 & $\begin{array}{l}1.416 \\
(0.219)\end{array}$ & $\begin{array}{c}-0.096 \\
(0.034)\end{array}$ & $\begin{array}{c}\text { Seasonal } \\
-0.671 \\
(0.568)\end{array}$ & $\begin{array}{c}\text { y Adjusted } \\
-0.090 \\
(0.050)\end{array}$ & 0.000 & 0.000 & 0.189 \\
\hline 2 & $\begin{array}{c}0.974 \\
(0.177)\end{array}$ & $\begin{array}{c}-0.042 \\
(0.025)\end{array}$ & $\begin{array}{c}0.447 \\
(0.308)\end{array}$ & $\begin{array}{c}-0.001 \\
(0.030)\end{array}$ & 0.000 & 0.000 & 0.234 \\
\hline 3 & $\begin{array}{c}0.636 \\
(0.140)\end{array}$ & $\begin{array}{c}-0.044 \\
(0.020)\end{array}$ & $\begin{array}{c}0.469 \\
(0.268)\end{array}$ & $\begin{array}{c}0.037 \\
(0.019)\end{array}$ & 0.000 & 0.000 & 0.119 \\
\hline 4 & $\begin{array}{c}0.342 \\
(0.131)\end{array}$ & $\begin{array}{c}-0.050 \\
(0.020)\end{array}$ & $\begin{array}{c}0.034 \\
(0.147)\end{array}$ & $\begin{array}{c}0.009 \\
(0.010)\end{array}$ & 0.082 & 0.025 & 0.635 \\
\hline 5 & $\begin{array}{c}0.340 \\
(0.131)\end{array}$ & $\begin{array}{r}-0.048 \\
(0.019)\end{array}$ & $\begin{array}{c}0.024 \\
(0.146)\end{array}$ & $\begin{array}{l}0.004 \\
(0.007)\end{array}$ & 0.101 & 0.026 & 0.792 \\
\hline 6 & $\begin{array}{c}0.369 \\
(0.126)\end{array}$ & $\begin{array}{c}-0.052 \\
(0.019)\end{array}$ & $\begin{array}{c}0.003 \\
(0.145)\end{array}$ & $\begin{array}{c}0.003 \\
(0.006)\end{array}$ & 0.049 & 0.011 & 0.801 \\
\hline 12 & $\begin{array}{l}0.286 \\
(0.105)\end{array}$ & $\begin{array}{r}-0.040 \\
(0.016)\end{array}$ & $\begin{array}{c}-0.041 \\
(0.151)\end{array}$ & $\begin{array}{c}0.002 \\
(0.006)\end{array}$ & 0.081 & 0.018 & 0.808 \\
\hline
\end{tabular}

Notes: The table contains unbiasedness test results for different releases of annualized monthly growth rates of Industrial Production over the period 1963.1-1998.12, based on data vintages for 1963.1-2001.1, and based on estimating equation (8) with $\gamma_{1}=\gamma_{2}=0$ imposed. The difference between these results and those reported in Tables 6 and 7 is that equation (8) imposes nonlinearity in the form of asymmetric business cycle effects on the unbiasedness test regression, while linearity is imposed when equation (4) is estimated (i.e. in Tables 6 and 7). See Table 6 for further details. 
Table 17: Unbiasedness of Real-Time Growth Rates of the Producer Price Index for Finished Goods - NL Business Cycle Model

\begin{tabular}{|c|c|c|c|c|c|c|c|}
\hline Release $k$ & $\alpha_{1}$ & $\beta_{1}$ & $\alpha_{2}$ & $\beta_{2}$ & $\begin{array}{l}\alpha_{1}=\alpha_{2}=0 \\
\beta_{1}=\beta_{2}=0\end{array}$ & $\begin{array}{l}\alpha_{1}=0 \\
\beta_{1}=0\end{array}$ & $\begin{array}{l}\alpha_{2}=0 \\
\beta_{2}=0\end{array}$ \\
\hline \multicolumn{8}{|c|}{ Seasonally Unadjusted } \\
\hline 1 & $\begin{array}{c}0.056 \\
(0.057)\end{array}$ & $\begin{array}{r}-0.020 \\
(0.013)\end{array}$ & $\begin{array}{c}0.020 \\
(0.185)\end{array}$ & $\begin{array}{c}-0.006 \\
(0.021)\end{array}$ & 0.669 & 0.317 & 0.945 \\
\hline 3 & $\begin{array}{c}0.058 \\
(0.057)\end{array}$ & $\begin{array}{c}-0.020 \\
(0.013)\end{array}$ & $\begin{array}{l}0.020 \\
(0.185)\end{array}$ & $\begin{array}{r}-0.006 \\
(0.021)\end{array}$ & 0.656 & 0.305 & 0.945 \\
\hline 4 & $\begin{array}{c}0.403 \\
(0.128)\end{array}$ & $\begin{array}{c}0.021 \\
(0.018)\end{array}$ & $\begin{array}{l}1.278 \\
(0.308)\end{array}$ & $\begin{array}{c}-0.028 \\
(0.027)\end{array}$ & 0.000 & 0.003 & 0.000 \\
\hline
\end{tabular}

Seasonally Adjusted

There are no cases where the NL model was found to be useful.

Notes: The table contains unbiasedness test results for different releases of annualized monthly growth rates of the Producer Price Index for Finished Goods over the period 1978.1-1998.12, based on data vintages for 1978.1-2001.1, and based on estimating equation (8) with $\gamma_{1}=\gamma_{2}=$ 0 imposed. Note that $\mathrm{k}=2$ has not been added to the top panel of the table because this case yields identical results to those for the $\mathrm{k}=3$ case. See Tables 6 and 16 for further details. 


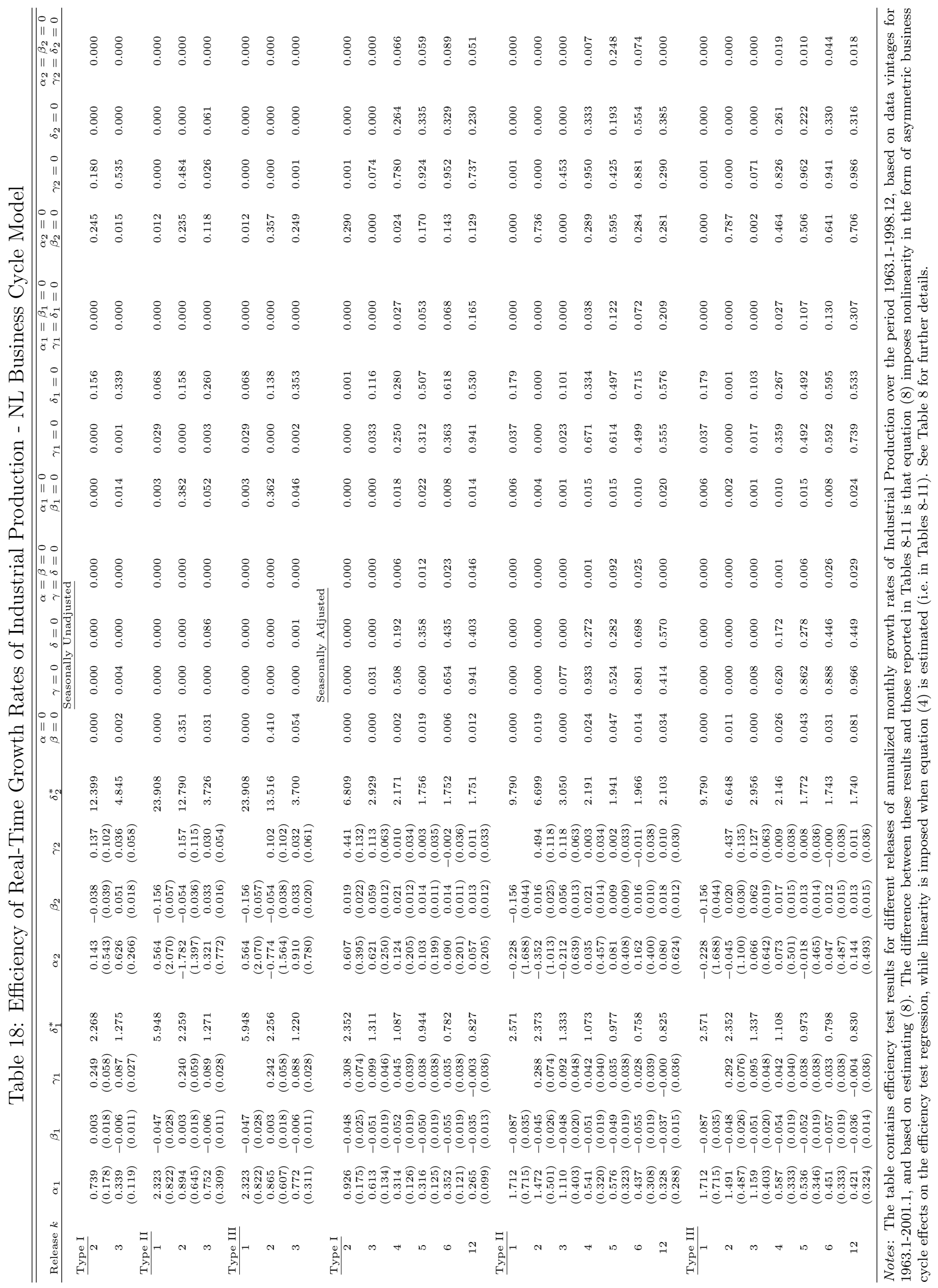




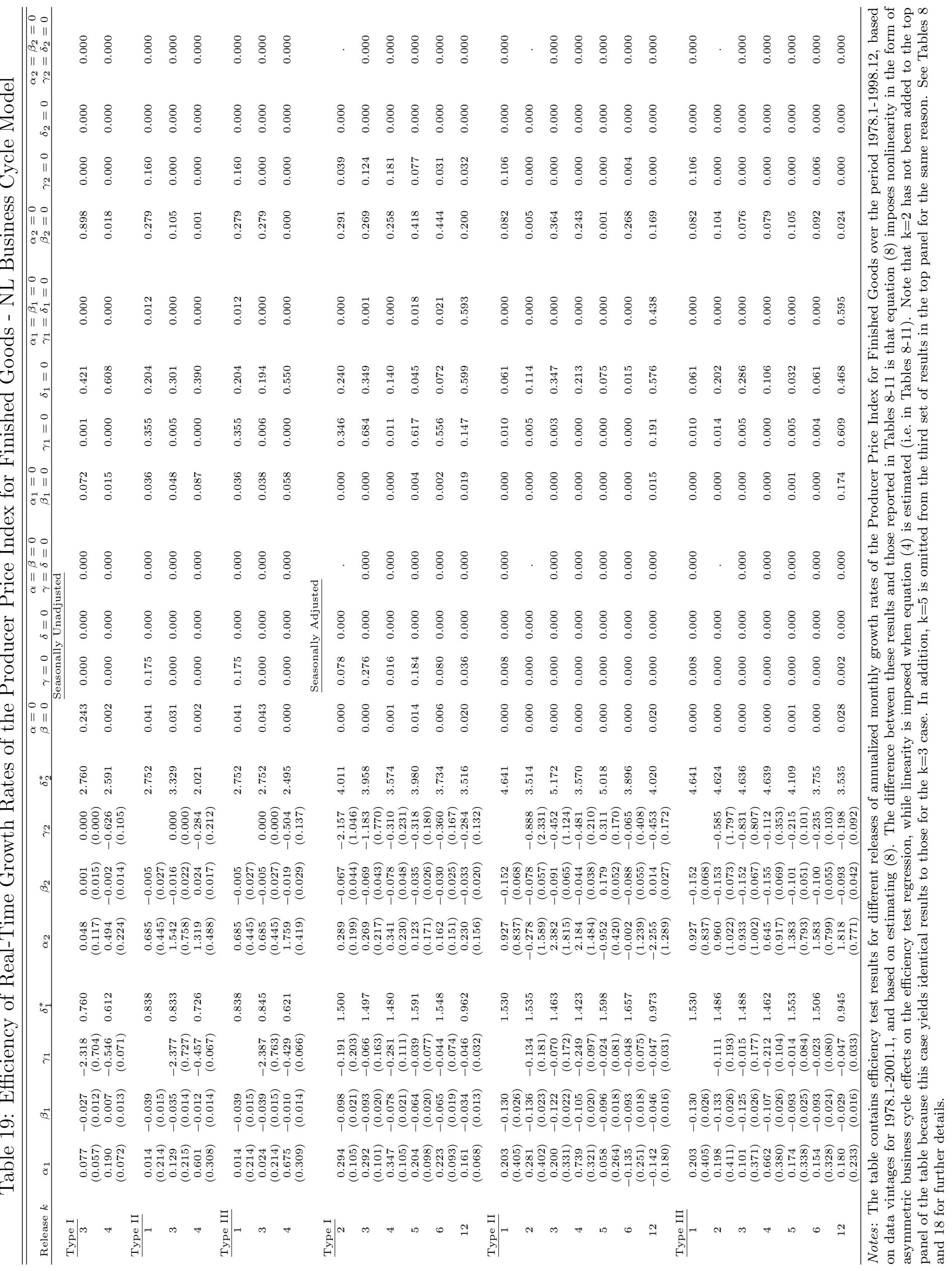




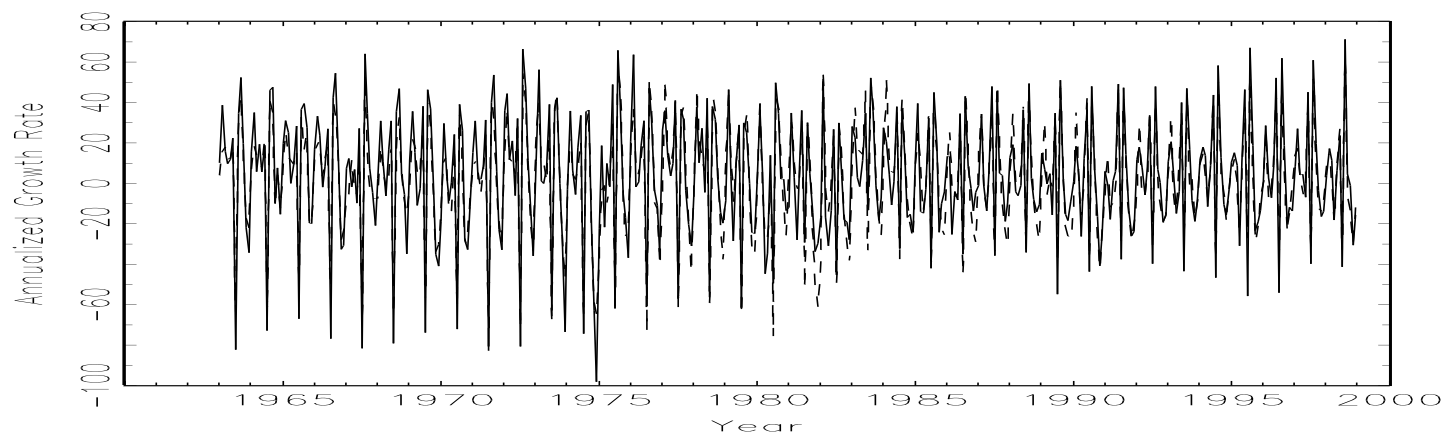

(a) First available (dashed line) and Fully revised (solid line) growth rates

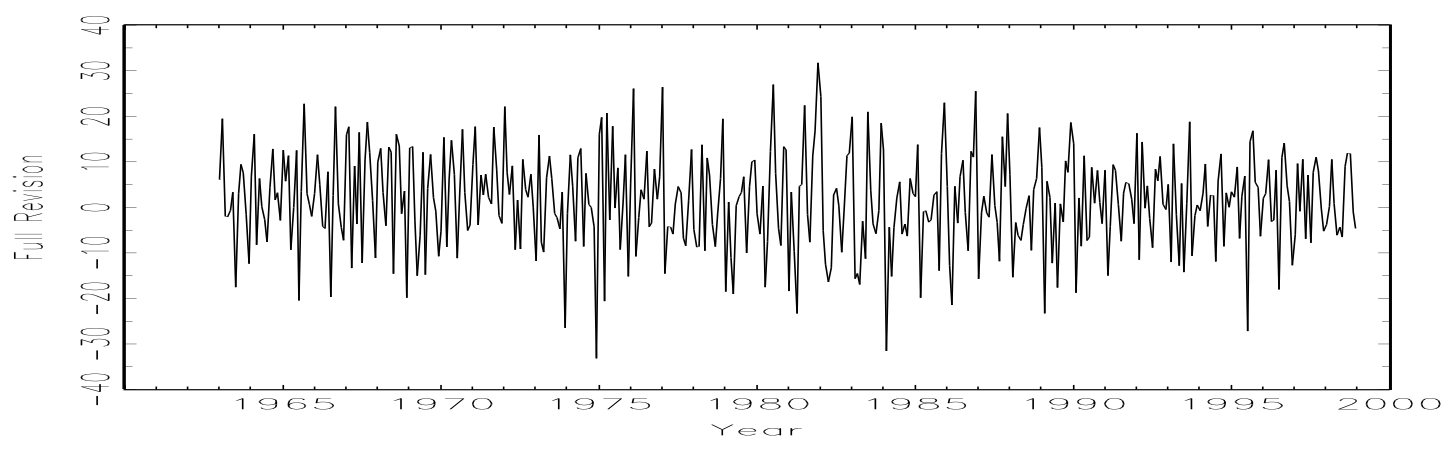

(b) Complete revision

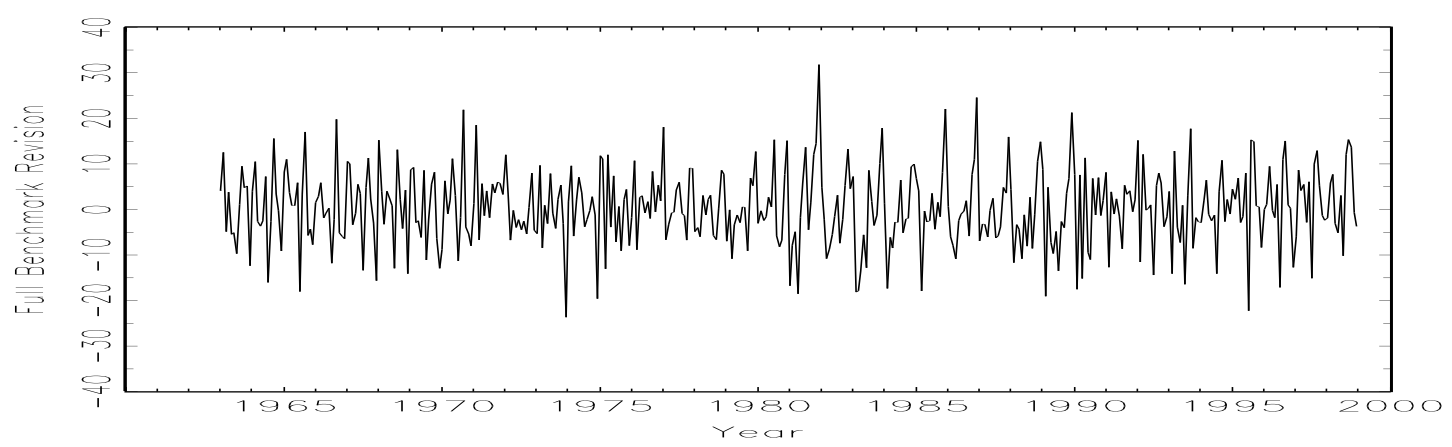

(c) Benchmark revision

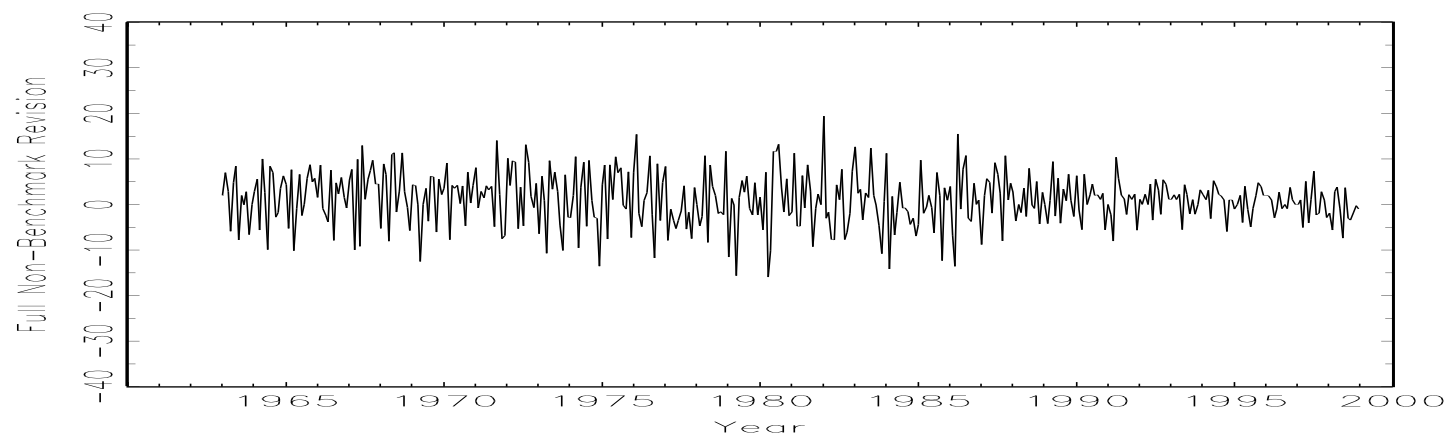

(d) Non-benchmark revision

Figure 1: Real-time monthly growth rates of seasonally unadjusted industrial production. 


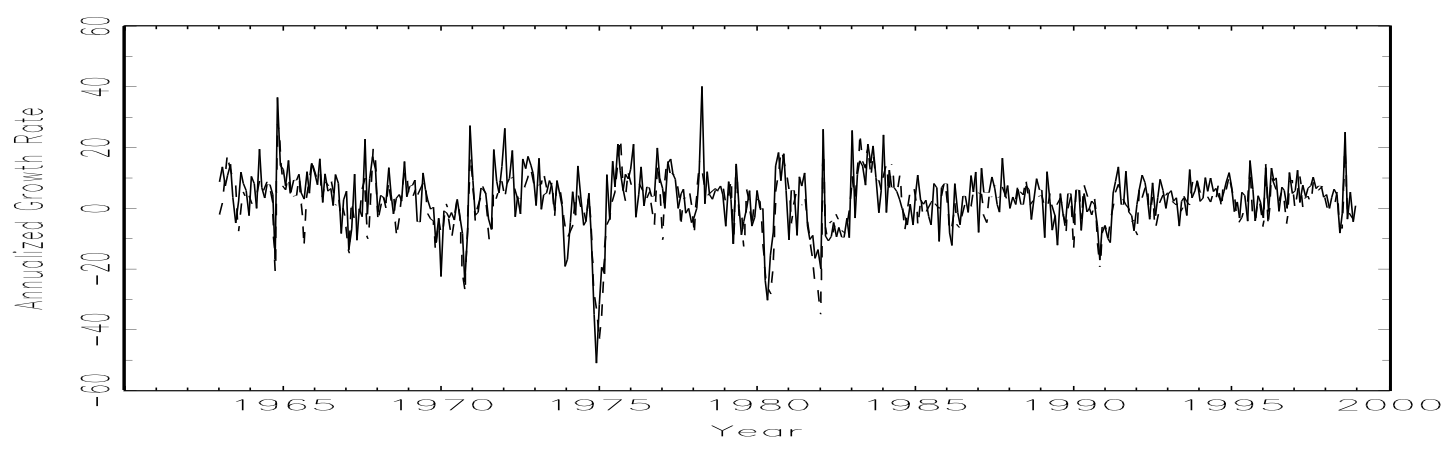

(a) First available (dashed line) and Fully revised (solid line) growth rates

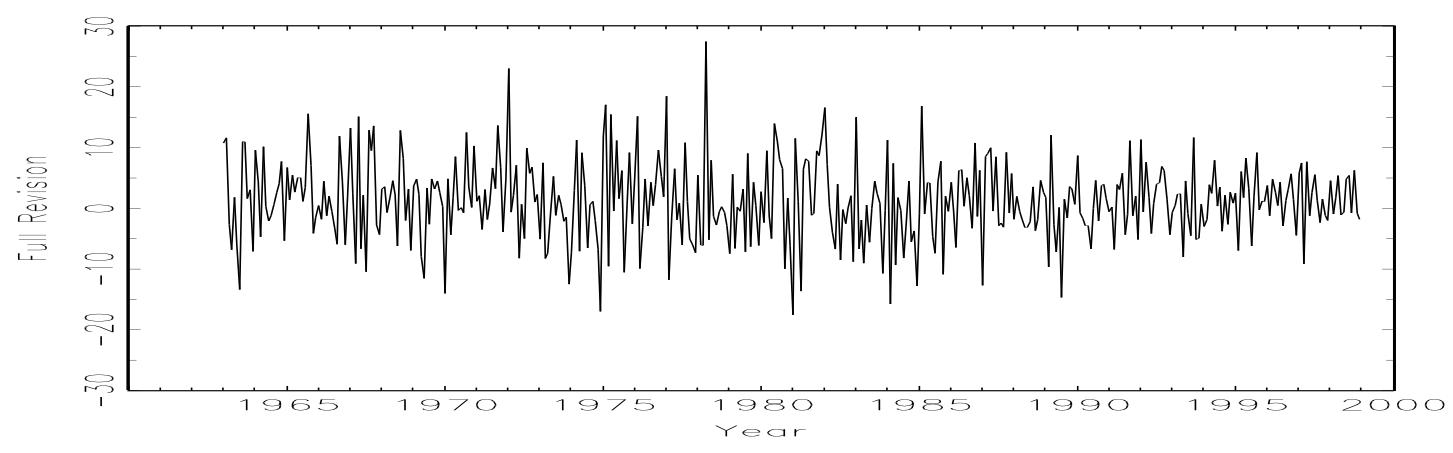

(b) Complete revision

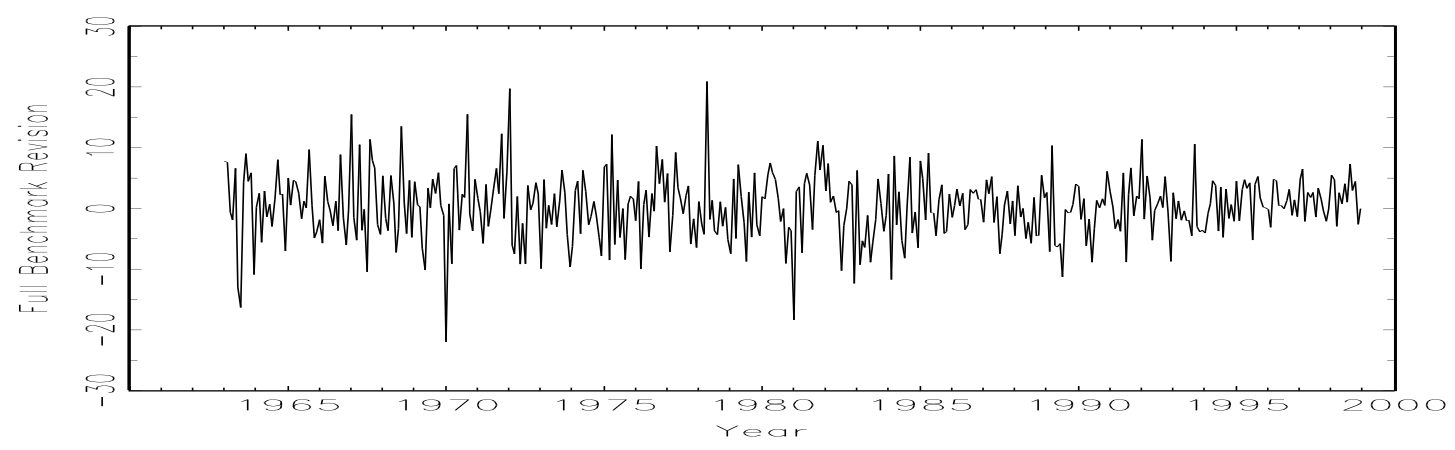

(c) Benchmark revision

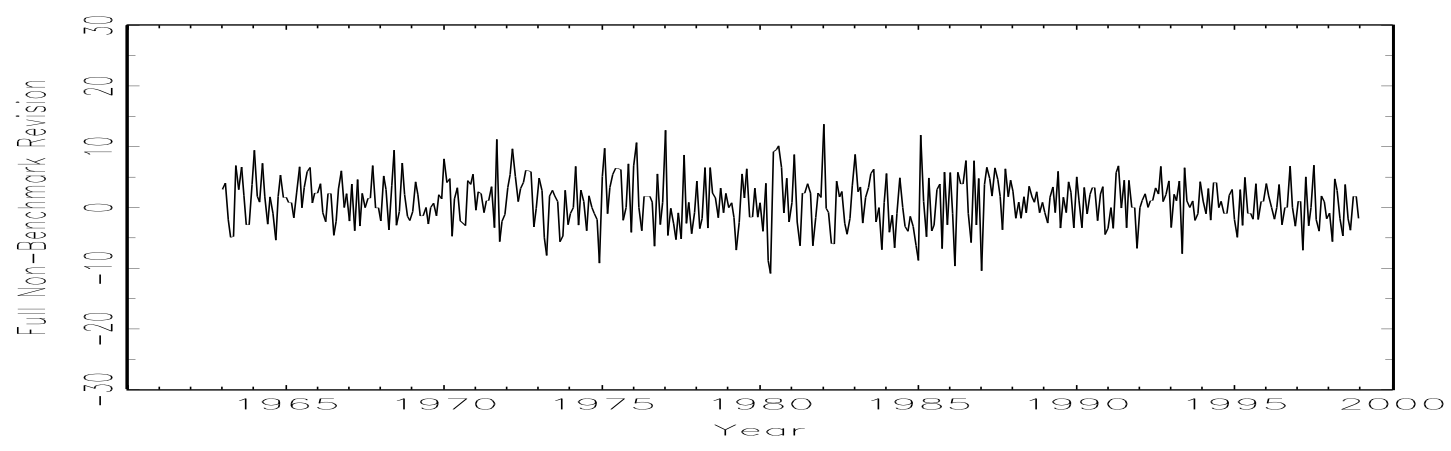

(d) Non-benchmark revision

Figure 2: Real-time monthly growth rates of seasonally adjusted industrial production. 


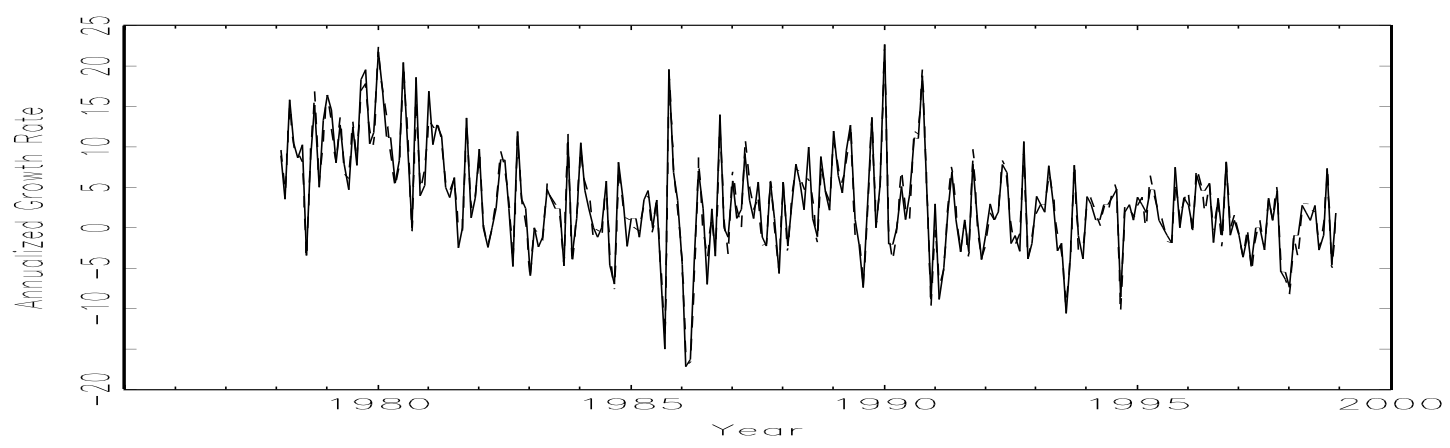

(a) First available (dashed line) and Fully revised (solid line) growth rates

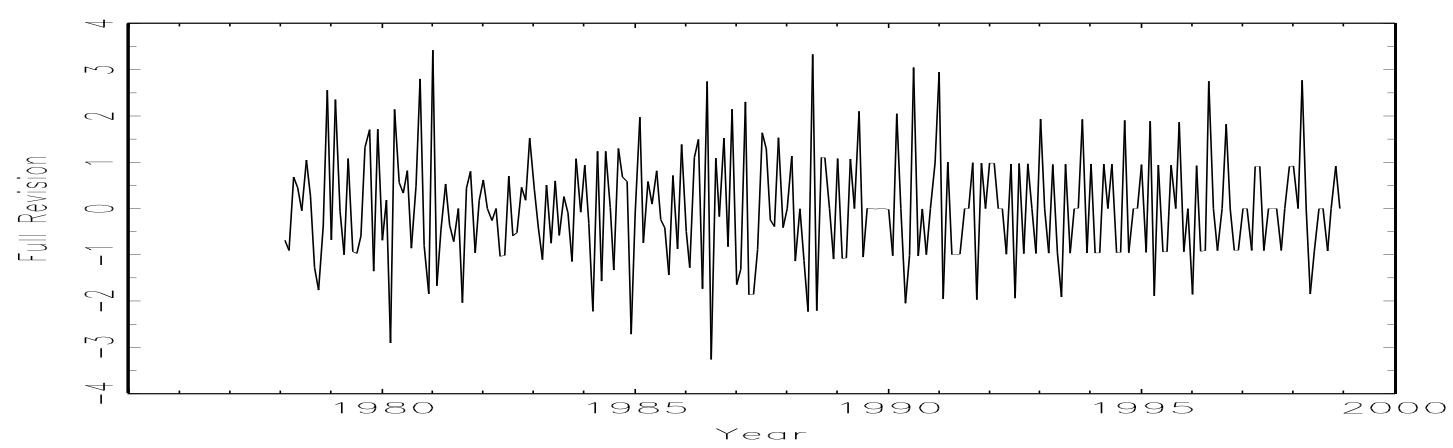

(b) Complete revision

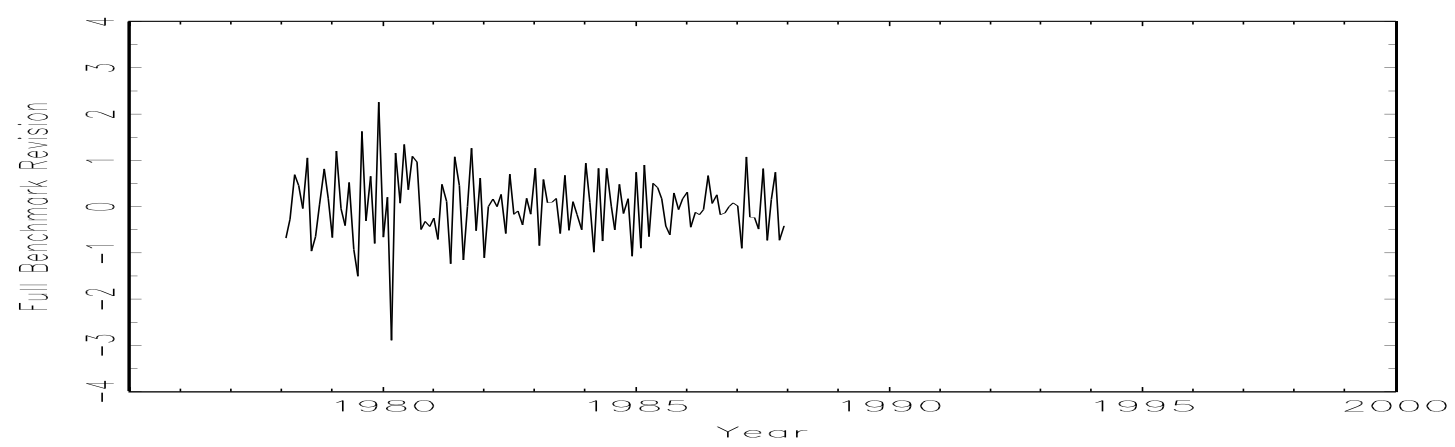

(c) Benchmark revision

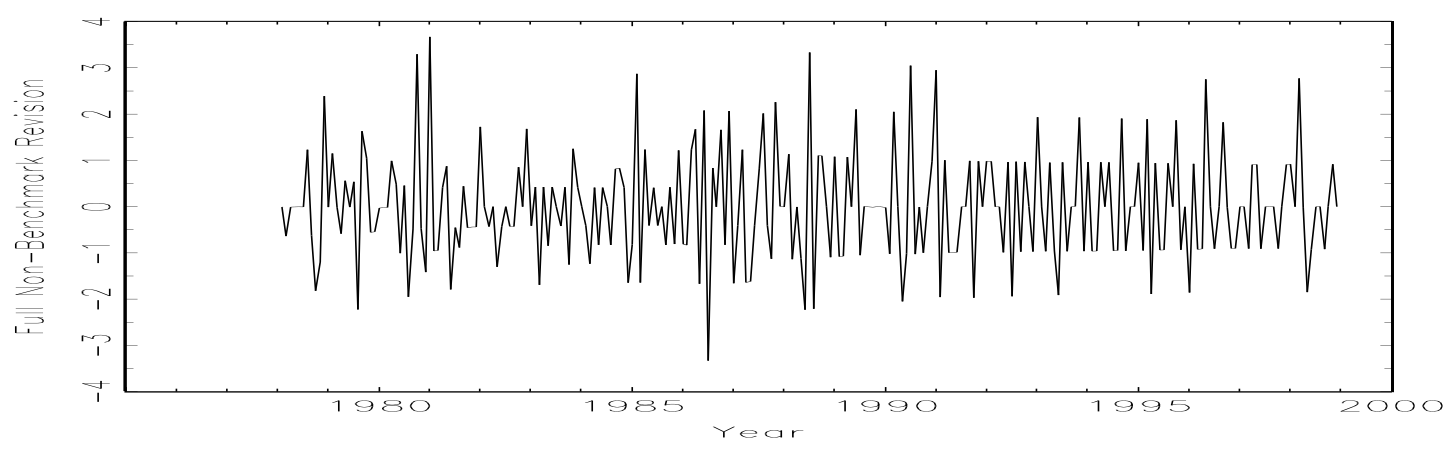

(d) Non-benchmark revision

Figure 3: Real-time monthly growth rates of seasonally unadjusted producer price index for finished goods. 


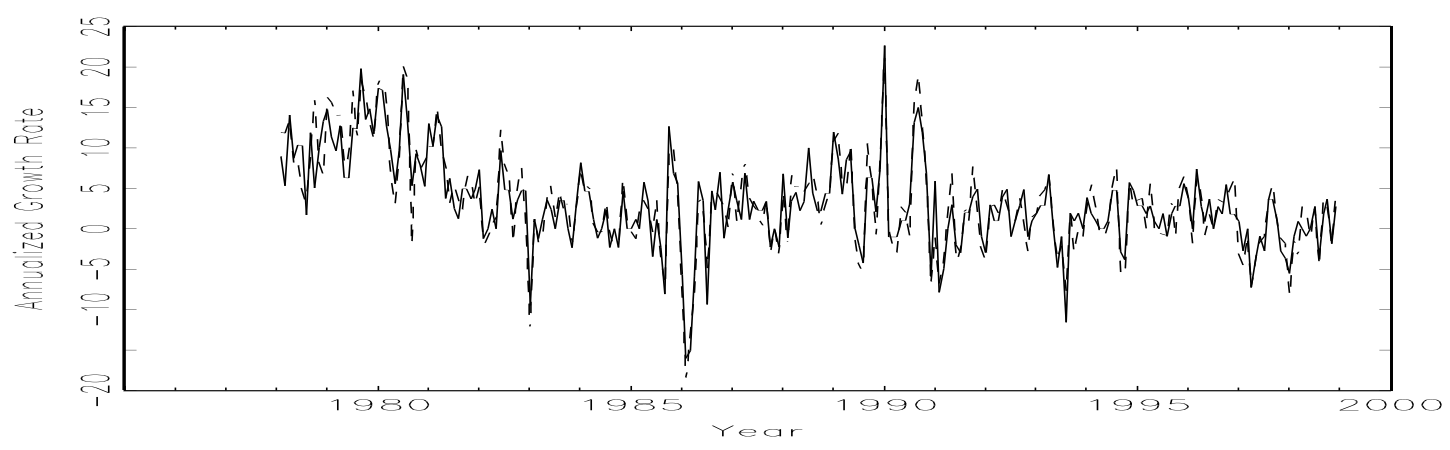

(a) First available (dashed line) and Fully revised (solid line) growth rates

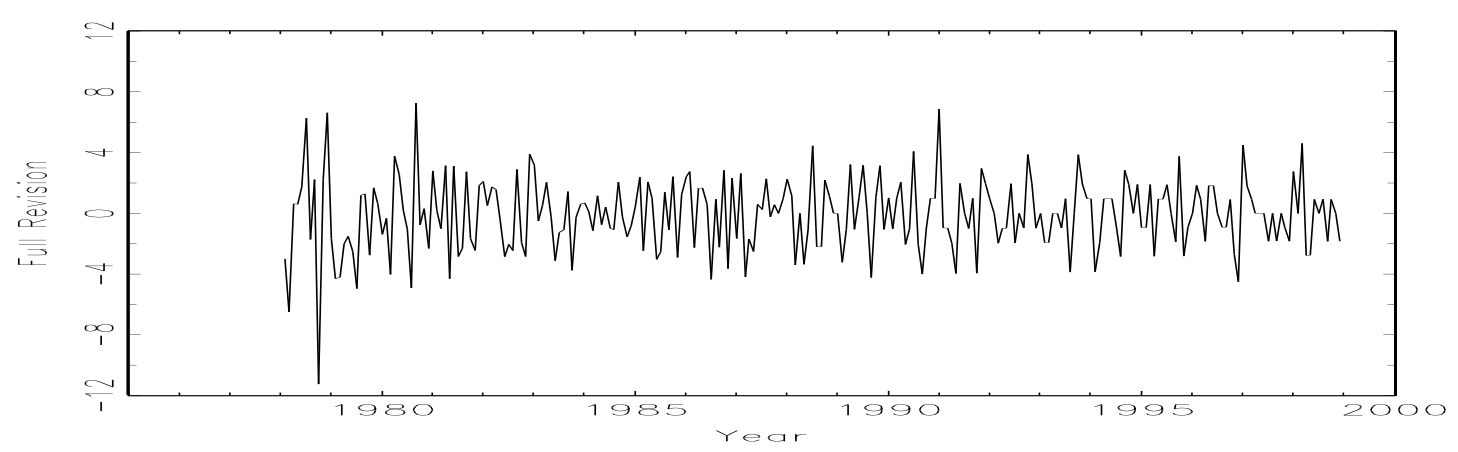

(b) Complete revision

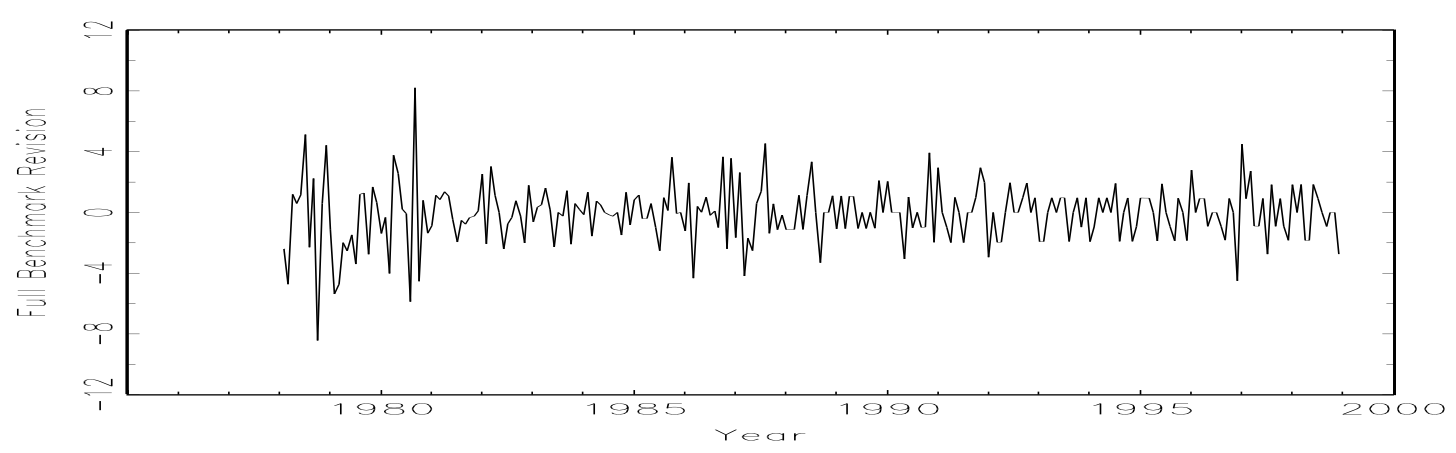

(c) Benchmark revision

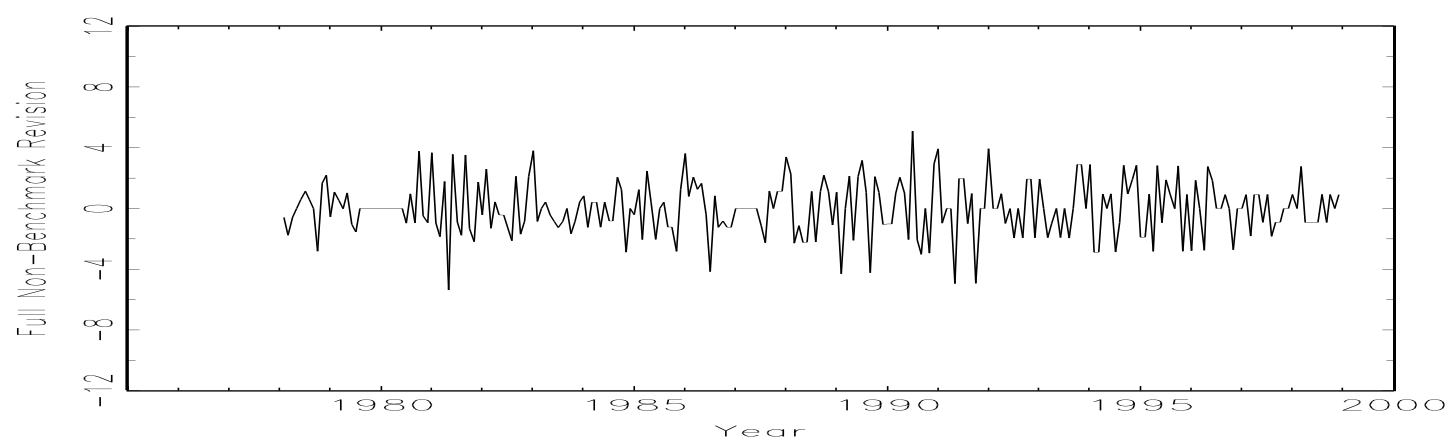

(d) Non-benchmark revision

Figure 4: Real-time monthly growth rates of seasonally adjusted producer price index for finished goods. 